Field Measurements of a Swell Band, Shore Normal, Flux Divergence Reversal

By

\author{
Shmuel G. Link
}

Submitted in partial fulfillment of the requirements for the degree of

Master of Science in Oceanographic Engineering

at the

MASSACHUSETTS INSTITUTE OF TECHNOLOGY

and the

WOODS HOLE OCEANOGRAPHIC INSTITUTION

June 2011

(C) 2011, Shmuel Link - All rights reserved.

The author hereby grants to MIT and WHOI permission to reproduce and to distribute publicly paper and electronic copies of this thesis document in whole or in part in any medium now known or hereafter created.

Signature of Author:

Joint Program in Oceanography / Applied Ocean Science and Engineering, Massachusetts Institute of Technology and Woods Hole Oceanographic Institution

May 6, 2011

Certified by:

Peter A. Traykovski, Associate Scientist with Tenure, Thesis Co-Supervisor, Applied Ocean Science and Engineering, Woods Hole Oceanographic Institution

Certified by:

John Trowbridge, Department Chair and Senior Scientist, Thesis Co-Supervisor,

Applied Ocean Science and Engineering, Woods Hole Oceanographic Institution

Accepted by:

David Hardt,

Chairman, Department Committee on Graduate Theses

Department of Mechanical Engineering, Massachusetts Institute of Technology

Accepted by:

James C. Preisig,

Chair, MIT/WHOI Joint Committee,

Applied Ocean Science and Engineering, Woods Hole Oceanographic Institution 


\title{
Field Measurements of a Swell Band, Shore Normal, Flux Divergence Reversal.
}

by

\author{
Shmuel G. Link \\ Submitted to the Joint Program in Oceanography / \\ Applied Ocean Science and Engineering \\ on May 6, 2011, in partial fulfillment of the \\ requirements for the degree of \\ Master of Science in Oceanographic Engineering
}

\begin{abstract}
Throughout this thesis we will discuss the theoretical background and empirical observation of a swell band shore normal flux divergence reversal. Specifically, we will demonstrate the existence and persistence of the energy flux divergence reversal in the nearshore region of Atchafalaya Bay, Gulf of Mexico, across storms during the March through April 2010 deployment. We will show that the swell band offshore component of energy flux is rather insignificant during the periods of interest, and as such we will neglect it during the ensuing analysis. The data presented will verify that the greatest flux divergence reversal is seen with winds from the East to Southeast, which is consistent with theories which suggest shoreward energy flux as well as estuarine sediment transport and resuspension prior to passage of a cold front. Employing the results of theoretical calculations and numerical modeling we will confirm that a plausible explanation for this phenomena can be found in situations where temporally varying wind input may locally balance or overpower bottom induced dissipation, which may also contravene the hypothesis that dissipation need increase shoreward due to nonlinear wave-wave interactions and maturation of the spectrum. Lastly, we will verify that the data presented is consistent with other measures collected during the same deployment in the Atchafalaya Bay during March - April 2010.
\end{abstract}

Thesis Supervisor: Peter A. Traykovski

Title: Associate Scientist with Tenure, Applied Ocean Physics \& Engineering, Woods Hole Oceanographic Institution

Thesis Supervisor: John Trowbridge

Title: Department Chair and Senior Scientist, Applied Ocean Physics \& Engineering, Woods Hole Oceanographic Institution 


\section{Contents}

1 Introduction $\quad 7$

1.1 Problem Definition . . . . . . . . . . . . . . . . . 7

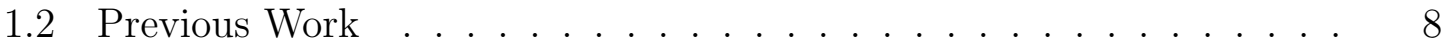

1.3 Overview of Present Work . . . . . . . . . . . . . . . . . 12

2 Methods 15

2.1 Site Description . . . . . . . . . . . . . . . . . . 15

2.2 Measurements . . . . . . . . . . . . . . . . . . . . . . . 17

2.2.1 Pertinent Units and Definitions _ . . . . . . . . . . 17

2.2 .2 Numerical Approximations . . . . . . . . . . . . . . . . . 18

2.2 .3 Incident Wave Energy _ . . . . . . . . . . . . . . . . . 19

2.2 .4 Wind Input $\ldots \ldots \ldots \ldots \ldots$

2.3 Analysis . . . . . . . . . . . . . . . . . . . 22

2.3 .1 Periods of Interest $\ldots \ldots \ldots \ldots \ldots \ldots$

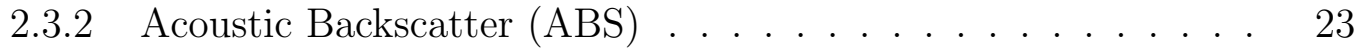

2.3 .3 Error Analysis . . . . . . . . . . . . . . . . . . . . 24

3 Results and Discussion $\quad 29$

3.1 Discussion . . . . . . . . . . . . . . . . . . . . . . . . . . . . 29

3.1 .1 Wind Input and SWAN _. . . . . . . . . . . . . 29

3.1 .2 Period of Interest $1 \ldots \ldots \ldots \ldots$

3.1 .3 Period of Interest $2 \ldots \ldots \ldots \ldots \ldots$

3.1.4 Burst Averaged ABS data . . . . . . . . . . . . 37 
3.1 .5 ABS Burst data . . . . . . . . . . . . . . . . 39

3.2 Results . . . . . . . . . . . . . . . . . . . 40

$\begin{array}{lll}4 \text { Conclusions } & 47\end{array}$

$\begin{array}{ll}\text { A Wind Input Calculations } & 49\end{array}$

$\begin{array}{ll}\text { B Wave Calculations } & 51\end{array}$ 


\section{Chapter 1}

\section{Introduction}

\subsection{Problem Definition}

Part of the initial interest in this problem stems from its heretofore minimal discussion in the literature. There are potentially many locations world-wide where such conditions exist, yet not many of them are well documented. Atchafalaya estuarine sediment is known to be transported (or advected) along the Northern coast of the Gulf of Mexico bordering Southwestern Louisiana. This allows for local progradation (or accretion) of coastline due to the dissipation of incident wave energy by a viscous coalesced layer of sediment on the seafloor [Eisma and Kalf, 1984, Kineke et al., 1996, Wright and Coleman, 1974]. Additionally, as the seafloor and viscous bottom layer are effectively transmitting information about their states back to the surface via the dissipation of wave energy throughout the water column, arriving at a better understanding of the mechanisms at play becomes more important. Developing a better sense of the temporal, spatial, and spectral balance between wind input, incident waves, and viscous dissipation is the overarching goal of this thesis. Fundamentally, if one knows the relationships between wind input, wave energy flux, and viscous dissipation, one could determine the condition of the seafloor given strictly surface measurements.

Wave supported gravity flows of the coalesced sediment fluid mud are considered in this analysis as it is hypothesized that these wave-supported sediment flows are 
an important mechanism in the movement of fluid mud along the bottom of the Atachfalaya Bay. In work on the flow of estuarine sediment in nominally similar locations, such as the Po river prodelta and the Eel river continental shelf, it was shown that energetic systems may allow for this type of sediment flow [Traykovski et al., 2000, 2007, Jaramillo et al., 2009]. The movement of the fluid mud is important specifically in the current context because fluid mud is the underlying cause of the incident wave energy dissipation. As such, if the bottom layer thickness changes due to an offshore flow, that will in turn effect the observed changes in incident wave flux, which in turn effect their spatial derivative, the flux divergence, and the general balance between sources and sinks of energy in the water column. Generally speaking, we are interested in explaining the general mechanisms by which a flux divergence reversal might occur.

\subsection{Previous Work}

Recent advances in the theory of viscous sublayers in numerical models for nearshore wave phenomena have extended previous theoretical work on two layer fluid models [Gade, 1958, Dalrymple and Liu, 1978, MacPherson, 1980, deWit, 1995]. Most recently, Kranenberg [2008], based on the work of deWit [1995], deWit and Kranenburg [1997], Winterwerp et al. [2007], has formulated an implicit solution to the problem. His solution, in terms of wavenumber, is formulated for an invicid upper layer where no constraints have been imposed on the layer thickness, and where the lower layer is considered viscous and shallow compared to the surface wavelength. This model differs from prior work in the assumptions made and thus the realizable regimes of the model, making this model much more applicable to the current analysis. Thus, for the physically relevant regimes of interest under consideration in this thesis, one can now iteratively solve for a complex wavenumber representing the travel and dissipation of a surface wave in the context of incident wave energy dissipation, as first

discussed by Gade [1958]. The real part of the wavenumber is (as always) inversely proportional to wavelength, and the complex part is proportional to the decay of the 
wave envelope (or equivalently dissipation of the incident energy).

Additionally, although these models explicitly allow for two sets of complex roots, which correspond to two unique modes of excitation, this work will primarily focus on only one of them - the surface (or external) mode. Specifically as it is the more physically relevant regime given that we are primarily concerned with the dissipation of surface wave energy by the viscous bottom layer ${ }^{1}$. Therefore, although the models do predict solutions for an internal (or baroclinic) mode, we will throughout this text, be primarily concerned with and refer to, the surface (or barotropic) mode.

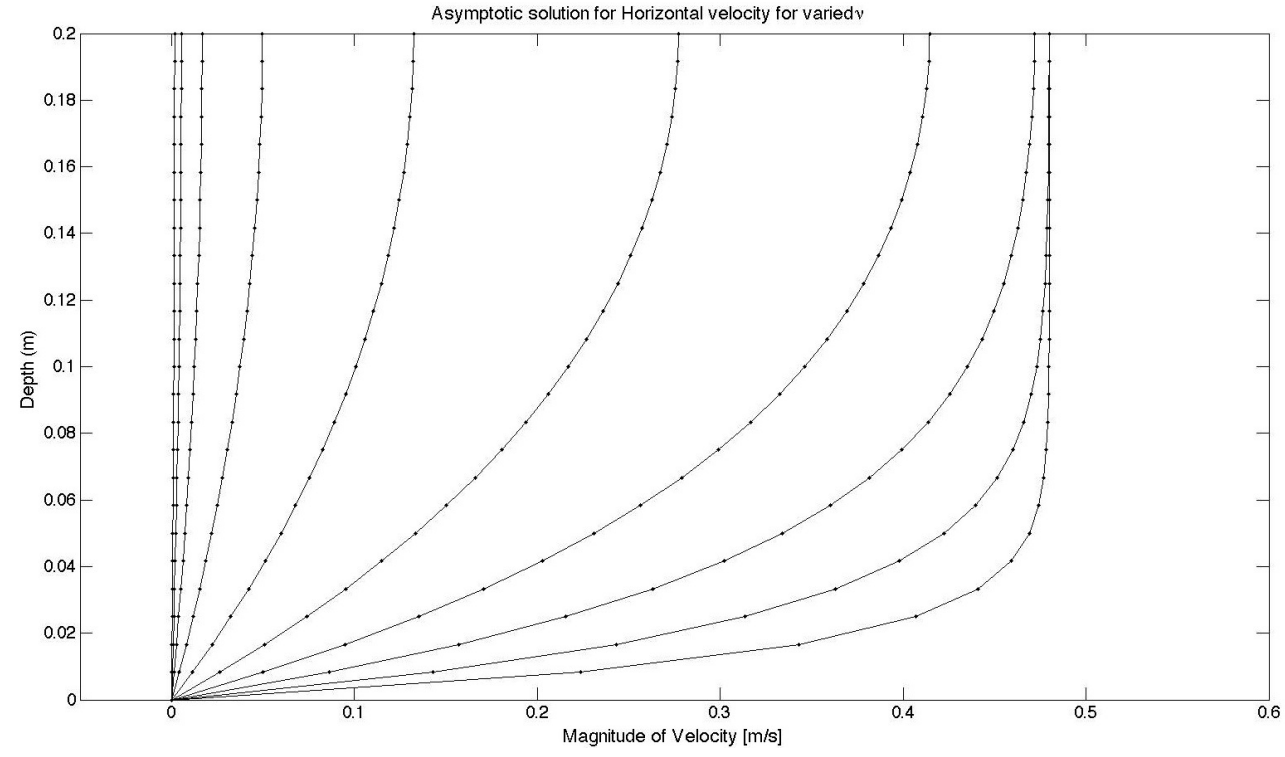

Figure 1-1: A numerical implementation of an asymptotic solution to Dalrymple and Liu [1978] developed by Trowbridge (personal communication 2010). For high $\nu$, as seen to the left of the figure, almost no motion is exhibited in the mud layer, while for low $\nu$, the layer moves almost like the water above it, and the Stokes boundary layer is very thin. Here, $\nu$ is plotted from $10^{-3}$ to $1 \mathrm{~m}^{2} / \mathrm{s}$ with $\frac{\rho_{1}}{\rho_{2}}=0.8913$ and $\omega=$ $0.89761 / \mathrm{s}$.

Turning now to consider the theoretical models of deWit [1995] and Kranenberg [2008], we see from dimensional considerations alone, that the Stokes boundary layer,

\footnotetext{
${ }^{1}$ As a matter of definition, the barotropic mode is when the surfaces of constant pressure and density must coincide, while for a baroclinic flow, that is not the case. Thus, the free surface and interface can have different signs, meaning that the interfacial displacement may potentially be much larger that the surface displacement.
} 
denoted here by

$$
\delta=\sqrt{\frac{2 \cdot \nu}{\omega}}
$$

will be an important parameter in the ensuing analysis; where $\omega$ is the angular velocity of the surface waves and $\nu$ is the kinematic viscosity of the mud layer. In looking at velocity profiles in the mud layer, it becomes apparent that as the kinematic viscosity is proportional to the Stokes boundary layer thickness ( $\delta$ in $[\mathrm{m}])$, as one increases, so does the other. This is demonstrated in Figure 1-1, where horizontal velocity is plotted for a range of kinematic viscosities and constant wave forcing. For very high $\nu$, the bottom layer hardly moves, if at all, and for very low $\nu$, the bottom layer will act as an extension of the overlying water layer and the corresponding bottom boundary layer will be very thin.
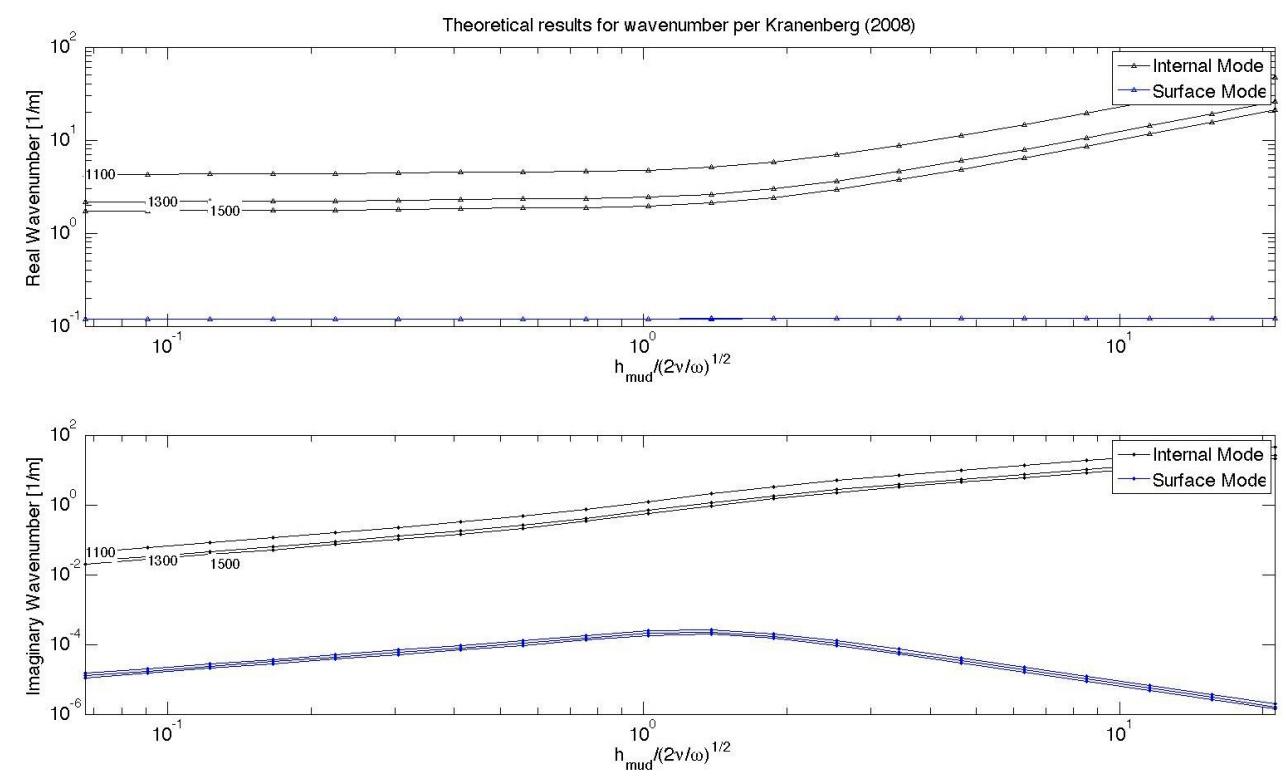

Figure 1-2: Solutions for the real and imaginary parts of wavenumber à la Kranenberg [2008] illustrating the insensitivity of the real part of the surface mode wavenumber to variation in kinematic viscosity, while the imaginary part of the wavenumber exhibits a distinct peak when normalized by the Stokes boundary layer thickness $(\delta)$. Here, $\omega=0.89761 / \mathrm{s}, h=7 \mathrm{~m}, \mathrm{a}=0.6 \mathrm{~m}$ (upper interfacial amplitude), $\mathrm{b}=0.1 \mathrm{~m}$ (lower interfacial amplitude), $\rho_{1}=1025 \mathrm{~kg} / \mathrm{m}^{3}$, and the the values on the plot represent the three values of $\rho_{2}$ calculated $-1100,1300$, and $1500 \mathrm{~kg} / \mathrm{m}^{3}$.

Thus, turning back to focus on the theoretical surface mode solution discussed previously, we see in Figure 1-2 that over the three orders of magnitude of normal- 
ized bottom layer thickness (the viscous mud layer thickness divided by the Stokes boundary layer thickness, $\tilde{h}=h_{m u d} / \sqrt{\frac{2 \cdot \nu}{\omega}}$ ), for which wavenumber was computed, the real part of the solution (in the upper plot) does not depend on the kinematic viscosity. The calculations were undertaken for three different lower layer densities (namely 1100, 1300, and $1500 \mathrm{~kg} / \mathrm{m}^{3}$ ) and as shown, the real part of the wavenumber remains unaffected. The real component of wavenumber for the surface mode is effectively that which would be calculated using linear wave theory for a bottom of similar depth $\left(\omega^{2}=g k \tanh (k h)\right)$. Looking now at the imaginary component of wavenumber for the surface mode (in the lower plot of Figure 1-2), we see that it exhibits a distinct peak when the normalized mud layer thickness is of order 1. This implies that there is a distinct and unique peak to the dissipation for the system over the band of physically relevant $\tilde{h}$ analyzed and described by Kranenberg [2008]. And again, these calculations were performed for three different lower layer densities, and as with the real component of wavenumber for the surface mode, the results were found to be quite insensitive to variations in the lower layer density.

Looking at the convex shape of the surface mode imaginary wavenumber curve in Figure 1-2, it becomes clear that although there is one peak in dissipation, wherein $\tilde{h}$ is $\mathrm{O}(1)$, the two extremes of the curve also bear note. To the right of the figure, when $\tilde{h}$ is $\mathrm{O}(0.1)$, the imaginary wave number decreases by an order of magnitude. This physically corresponds to a situation in which there is either very little fluid mud present or a very thick Stokes boundary layer. On the other end of the figure, the opposite is true, and for an $\tilde{h}$ of $\mathrm{O}(10)$ we would need a correspondingly thick mud layer or exceedingly thin Stokes boundary layer, to enter this regime.

The exact location of the peak in the imaginary part of the wavenumber on the $\tilde{h}$ axis is a matter of some discussion in the literature. $\mathrm{Ng}$ finds it to be at approximately 1.55 , while Gade shows it to be around 1.2 given his shallow water assumption. Dalrymple and Liu show peaks in-between those. While Kranenberg, based on the work of deWit [1995], deWit and Kranenburg [1997], makes explicit mention of this problem, and attempts to define regimes of interest for physically relevant situations and thus resolving the confusion, in many cases these differences are due to assumptions 
surrounding the derivations. For instance, Gade's shallow water assumption, or Dalrymple and Liu's assumptions of either a lower layer which is thick when compared to the viscous boundary layer or of a normalized mud layer thickness $(\tilde{h})$ which is larger than one. Thus it becomes difficult to unambiguously reconcile the differences between these derivations and define a unique imaginary wavenumber peak in the regime of interest.

\subsection{Overview of Present Work}

Throughout this work we will attempt to investigate the effect that a shelf normal gravity-flow of estuarine sediment (which can be present as a fluid mud) may have on the observed flux divergence reversal. We will do so by exploring the various mechanisms which might effect the energy balance and thus the dissipation of incident wave energy by looking at in situ measurements and numerical models. It has been previously shown that offshore flow of fluid mud may play a significant role in understanding the dynamics of the balance between dissipation and growth of energy in the nearshore water column [Traykovski et al., 2000, 2007, Hsu et al., 2007].

The two extrema in the theoretical dissipation curve discussed previously have implications to the analysis of the field data, in that by looking at the calculated in situ dissipations one can begin to discern how close to or far away from the peak the system is ${ }^{2}$. Employing a combination of wind, pressure, and ABS data, we will then begin to infer to which side of the maxima the system was tending based on the energy balance. Then, with numerical simulations we will begin to quantify the effect each mechanism might have on the system.

Flux divergence is the change of wave energy flux from one spatial location to another, and in the context of this thesis, from one instrumented station to the next as the wave energy travels onshore. In the case of the data to be presented, a shore-

\footnotetext{
${ }^{2}$ It should be noted, that in personal communication, Traykovski [2011] alluded to the fact that previous datasets analyzed reveal that observed systems are generally to the right of the theoretical dissipation peak $\left(h_{m u d}>\sqrt{\frac{2 \cdot \nu}{\omega}}\right)$, rather than to its left $\left(h_{m u d}<\sqrt{\frac{2 \cdot \nu}{\omega}}\right)$ as viscosity is usually low due to low concentrations of estuarine sediment.
} 
normal flux divergence is computed, meaning that energy fluxes are calculated for each of the three deployed stations and subsequently rectified to shore-normal, at which point flux divergences can be calculated. Additionally, as discussed in Kranenberg [2008], the flux divergence divided by the incident energy flux is proportional to the imaginary part of the surface mode wavenumber and the dissipation of the incident waves. This fact highlights the importance of the numerical approximations to be employed in this work, because for the three stations deployed there are measures of flux (one at each station), but only two independent measures of flux divergence.

Finally, mention must be made of what is meant by a flux divergence reversal. In essence, a flux divergence reversal is an increase in the energy flux between two points normal to shore for waves traveling shore-normal over a viscous bottom. This is considered a reversal as a viscous bottom should typically dissipate incident wave energy. As will be seen in the March 2010 data, there are temporary increases in the flux divergence in the $5 \mathrm{~m}$ to $3 \mathrm{~m}$ segment as compared to that calculated for the $7 \mathrm{~m}$ to $5 \mathrm{~m}$ segment, indicating that the dissipative bottom layer is either not present or is locally being overpowered by external forcing.

Thus, the important factors surrounding the occurrence and development of the hypothesized swell-band, shore-normal, flux divergence reversal will be investigated in the hopes of understanding the role they play in this phenomena. 


\section{Chapter 2}

\section{Methods}

\subsection{Site Description}

The data analyzed in this thesis comes specifically from a deployment in the Atchafalaya Bay of the Gulf of Mexico, with three deployed stations at 3m, 5m, and $7 \mathrm{~m}$ water depth. The $3 \mathrm{~m}$ station was approximately $1.8 \mathrm{Km}$ from shore, and the spacing between the stations was approximately $0.7 \mathrm{Km}$ and $1.2 \mathrm{Km}$ respectively. The overall slope of the bottom is particularly gradual with a rise of $4 \mathrm{~m}$ in approximately 2.1 Km. Values for these spacings were determined via GPS coordinates collected during the deployment of the insturmentation ${ }^{1}$. It should be noted that the array normal (azimuthal) angle was found to be approximately $4^{\circ}$, and as such, the directional data collected is corrected to account for this slight difference. Finally, wind data collected separately, during an overlapping deployment was also analyzed in the context of this work.

Estuarine sediment from the Atchafalaya river plume is one of the major sources of suspended sediment in the (local) water column and mud along the seafloor of the eastern portion of the Chenier Plain coast. This is because sediment from the Atchafalaya is predominantly transported along the Northern Gulf Coast from East to West while making its way offshore [Kemp and Wells, 1981, Roberts et al., 1989].

\footnotetext{
${ }^{1}$ The length of the array was on the order of $2.1 \mathrm{Km}$, thus curvature of the earth was ignored and a cartesian coordinate system was employed with $0^{\circ}$ and $360^{\circ}$ for North (as is convention) throughout this work.
} 
For context within the scope of this work, the data being analyzed came from a sensor array deployed in a transition zone between prograding (accreting) coastline, and a zone of rapid coastal erosion [Huh et al., 2001, Draut et al., 2005b]. Figure 2-1 presents a schematic representation of Atchafalaya estuarine sediment transport and the relative location of the deployed array, where as can be seen, the extent of the accretion zone is limited by the influx of suspended estuarine sediment.

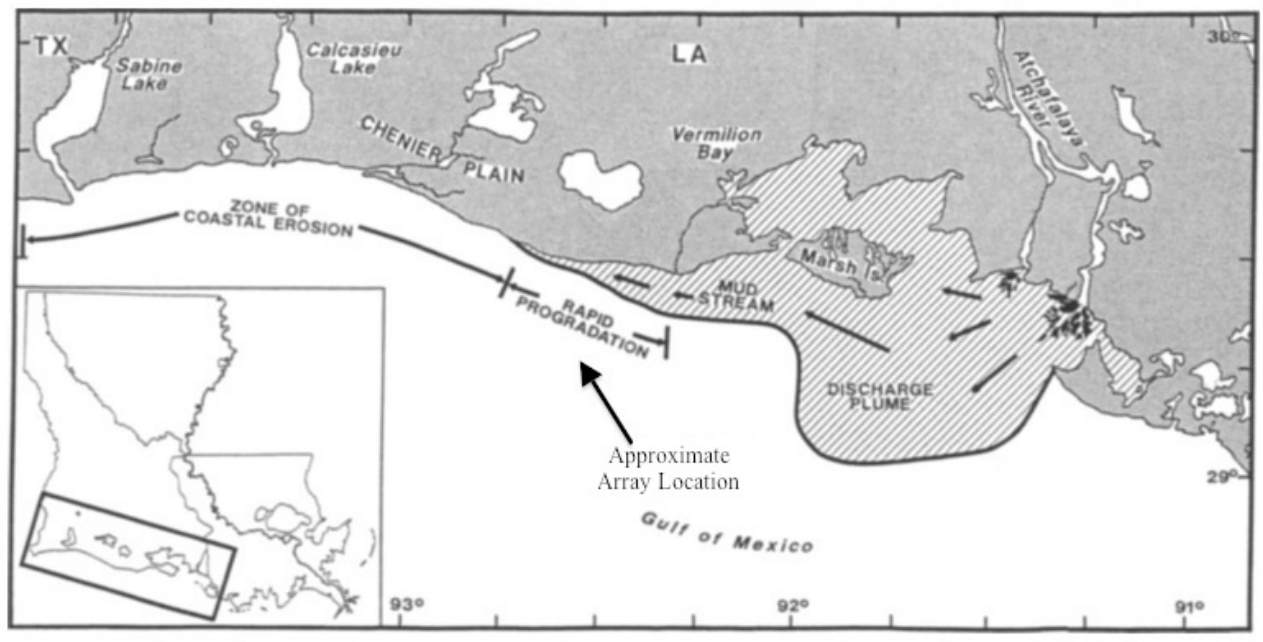

Figure 2-1: A schematic representation of the estuarine sediment transport from the Atchafalaya River into the Gulf of Mexico, and the approximate location of the sensor array. Adapted from Huh et al. [2001].

The rate of coastal accretion along the Eastern portion of the Chenier Plain coast is primarily governed by two competing factors; namely, the rate of estuarine sediment deposition, and the dissipation of incident wave energy [Crout and Hamiter, 1981, Draut et al., 2005a]. Thus, the local presence of the estuarine sediment is notable in that it can counteract the otherwise erosional effects of the incident wave field on the coastline, whereas adjacent pieces of coastline to the west are seen to be receding [ibid].

It should also be noted that during the winter months, from November through March, the Northern Gulf Coast typically sees the passage of between 20 and 40 cold fronts [Crout and Hamiter, 1981, Roberts et al., 1989]. In general terms, these weather patterns consist of cooler, denser air flowing East to Southeast, followed by warmer, less dense air from the West to Northwest with overturning and mixing 
occurring where the air masses meet. Typically, the effects of cold front passage can last anywhere between a few hours to days depending on the weather system which follows.

Our interest in these cold fronts lies in determining what, if any, effect the passage of the cold fronts might have on the observed flux divergence reversal in terms of the aforementioned swell-band wave energy balance. Particularly, we are interested in the the setup to these events, or the East to Southeasterly winds which precede the cold fronts passage, as there seems to be a very distinct correlation between the sustained peak wind speed and the observed swell-band flux divergence.

\subsection{Measurements}

\subsubsection{Pertinent Units and Definitions}

To preface the discussion of the data collected during the deployment, it is best to first define important terms (Table 2.1). Also, as the concept of a flux divergence may not be intuitively obvious, we will herein attempt to define not only what the flux divergence represents, but also why it is important.

In the ensuing analysis, we will be looking at a predominantly swell-band phenomenon. Therefore, all integrated quantities such as significant wave height $\left(H_{s i g}\right)$, energy density $(\bar{E})$, etc. are calculated from their respective spectra by numerical integration over the swell-band. For our purposes, the swell-band is defined as being the frequency band between $0.05 \mathrm{~Hz}$. and $0.2 \mathrm{~Hz}$. (corresponding to wave periods of 5 to 20 seconds). Additionally, if and when discussed, the sea band is similarly defined as being between $0.2 \mathrm{~Hz}$. and $0.3 \mathrm{~Hz}$. (which would correspond to wave

\begin{tabular}{||c|c|c||}
\hline Variable: & Name: & Units: \\
\hline$F=\bar{E} \cdot C_{g}$ & Energy Flux & $\mathrm{W} / \mathrm{m}$ \\
\hline $\mathrm{dF} / \mathrm{dx}$ & Flux Divergence & $W / m^{2}$ \\
\hline$(\mathrm{dF} / \mathrm{dx}) / \mathrm{F}$ & Dissipation & $m^{-1}$ \\
\hline
\end{tabular}

Table 2.1: Important variables in the analysis of the March 2010 deployment and the discussion of the observed flux divergence reversal. 
periods of approximately 3 to 5 seconds). A more complete discussion is presented in Appendix B

Throughout this thesis the focus will be on two specific 'events', (or observed occurrences) of the aforementioned flux divergence reversal. They were chosen as they exhibited the longest temporal duration of the phenomena - greater than 12 hours in each case and as such will be referred to in chronological order as 'period of interest one' and 'period of interest two'. It should be noted though, that there were at least six 'events' where the flux divergence reversal persisted for longer than three hours during this deployment.

\subsubsection{Numerical Approximations}

A number of numerical and physical approximations were necessitated not only by the sparsity of the data sets (spatial, temporal, spectral), but by physical limitations as well. Specifically, as all three instrumented stations were impacted at least once by vessels during the deployment window, a number of instruments ceased to function, or began to return erroneous data. Thus, one of the primary assumptions underlying this thesis is that the angular (directional) distribution of the wave spectrum is consistent along the length of the array. This assumption should prove to be fairly robust, since not only is the overall slope of the bottom approximately $1 / 500$, but the most nearshore sensor is nearly $1.8 \mathrm{Km}$ from shore. And as a means of validating this assumption, from the spectral wave direction data which was available, the refraction coefficient in the swell-band during a representative period was determined to be approximately 0.9 . This implies that in an ensemble sense, waves did not have to 'turn' or refract very much in order to be shore-normal by the time they passed the $3 \mathrm{~m}$ station $^{2}$. Additionally, throughout this work, when calculating flux divergences, a first order finite difference was employed, which yields errors on the order of the station spacings which are, again, $1.2 \mathrm{Km}$ between the $7 \mathrm{~m}$ and $5 \mathrm{~m}$ stations and 0.7 $\mathrm{Km}$ between the $5 \mathrm{~m}$ and $3 \mathrm{~m}$ stations respectively.

\footnotetext{
${ }^{2}$ Dean, Robert G., and Robert A. Dalrymple. Water Wave Mechanics for Engineers \& Scientists. World Scientific Publishing Company, 1991. Print. - Whereby they define the refraction coefficient,
} 
It is abundantly clear that all three instrumented stations were impacted, not only from the suddenly erroneous data that some sensors began returning, but also from visibly damaged sensors recovered. Thus, although both acoustic and pressure sensors were deployed, the primary dataset employed and analyzed in this thesis is from pressure sensors. Yet, via linear wave theory it is possible to calculate velocity and energy flux from the pressure signals, presuming one knows the height of the sensor from the free surface. These calculations are discussed in greater detail in Appendix B. This then leads to the supposition that even if the stations were impacted that the vertical distance of the pressure sensor did not change drastically.

The measurements from each station were collected with a Nortek Vector Acoustic Doppler Velocimeters (ADV) where, although the ADV data will not be presented due to problems with motion and alignment of the sensors and thus with the acoustic datasets, the pressure data collected by a piezoresistive sensor on the same instrument seemed to be not only self consistent, but also consistent with other pressure measures collected from other instrumentation at the same stations.

\subsubsection{Incident Wave Energy}

For a more general consideration of the incident wave field, given a general form of the wave energy equation:

$$
\frac{\partial \bar{E}}{\partial t}+\frac{\partial}{\partial x}\left(\bar{E} \cdot C_{g}\right)=S
$$

the focus will be primarily on the $\frac{\partial}{\partial x}\left(\bar{E} \cdot C_{g}\right)$ term as well as the right hand side, and although there are both temporal and spatial components to the wave energy flux; in this thesis, we will be primarily concerned with the spatial variation of the flux density, as opposed to its temporal variation. There are a number of related reasons for this omission but fundamentally, the reason is that the variability in $\bar{E}$ is over a much longer time frame than the time required for wave energy to propagate along the length of the array at speed $C_{g}$.

$K_{r}=\left(\frac{b_{0}}{b_{2}}\right)^{1 / 2}=\left(\frac{\cos \theta_{0}}{\cos \theta_{2}}\right)^{1 / 2}$ (which is effectively another way of thinking of Snell's law) for $\theta$ being the angle from shore-normal, $\theta_{0}$ being the initial wave angle, and $\theta_{2}$ being the wave direction at the onshore station. 


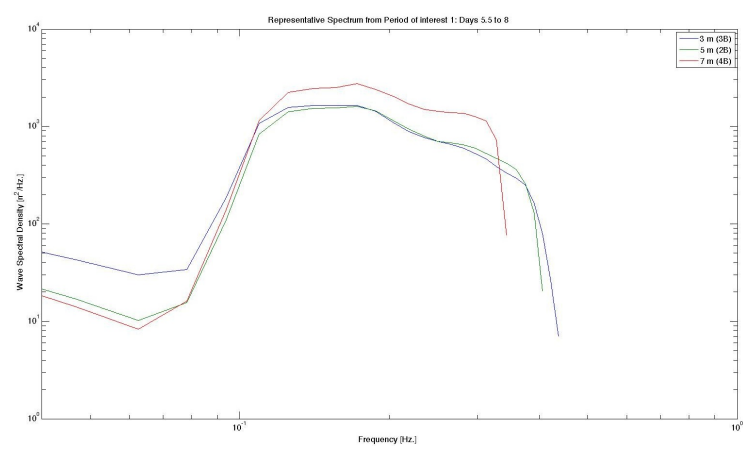

(a) Wave Spectral Density - days 5.5 to 8

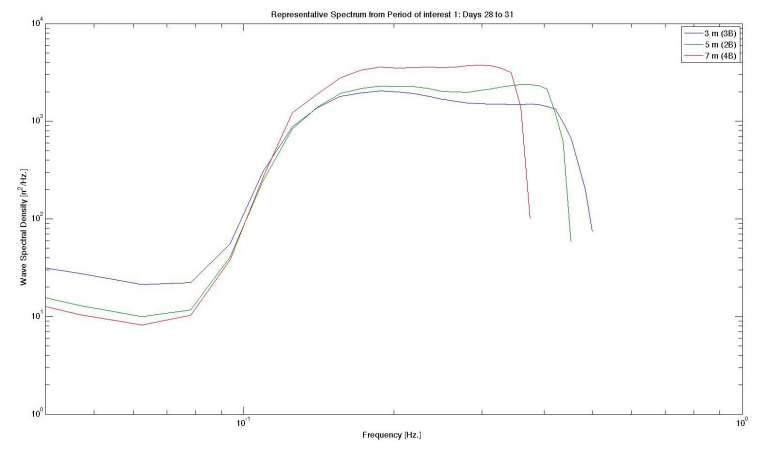

(b) Wave Spectral Density - days 28 to 31

Figure 2-2: Representative wave spectral densities plotted over the energetic portions of the first and second periods of interest.

If we expand the right hand side of Equation 2.1 to examine the specific sources and sinks of energy ${ }^{3}$ which potentially effect our system, there are five that bear discussion. Wind input to the system, white capping (a wave steepness effect), bottom induced dissipation, depth induced surf break, and non-linear wave-wave interaction (both triads and quadruplets) act as sources or sinks of energy. In particular, bottom induced dissipation is really a catch-all term used for effects such as bottom friction, percolation losses due to a porous bottom, bottom motion, or bottom irregularities, and for our discussion is a proxy for the effects that fluid mud has on incident waves.

Given that the fetch of the array was limited, we can make an assumption to ignore the quadruplet non-linear wave-wave interactions, as quadruplet effects primarily act over longer distances (many wavelengths) than we are investigating [Barnett, 1968, Carter, 1982]. Triad wave-wave interactions on the other hand may be a source of apparent dissipation for higher wind speeds (greater than $10 \mathrm{~m} / \mathrm{s}$ ) and may act to marginally increase the variance of the wind spectrum ${ }^{4}$ but can be shown in numerical simulations to primarily act outside the frequency band under consideration. Additionally, as we are investigating a swell-band phenomena, the effects of white capping as a means of energy dissipation will be minimal [Hasselmann, 1974]. Similarly, knowing that the waves during most of the deployment were almost always less than $1 \mathrm{~m}$

\footnotetext{
${ }^{3}$ Spectrally - so that we are still considering energy density per hertz.

${ }^{4}$ This effect would need to be analyzed in greater detail in order to ascertain its limited impact - which is beyond the scope of this thesis.
} 
in height it is likely safe to ignore depth induced surf break. Thus, equating the remaining terms, there need be a net balance in the wave energy equation between wind input, the observed flux divergence, and bottom induced dissipation in the system.

\subsubsection{Wind Input}

In order to better understand the wind input interaction, we have turned to a number of semi-empirical relationships which have been developed to describe the effect that energetic wind events have on the wave energy balance. These are some of the same relations employed by numerical models such as Simulating WAves Nearshore $(\mathrm{SWAN})^{5}$, and for the first and second-generation model formulations employed here ${ }^{6}$ one can evaluate the relations in closed form for a given frequency range and set of experimental parameters. In particular, given values for flux density per hertz $(\bar{E}$ in $J / m^{2} \cdot H z$.), water depth, wavenumber, and spectral distributions of wind and wave directions, these calculations yield that an incident wind forcing of $10 \mathrm{~m} / \mathrm{s}$ imparts between 0.05 and $0.1 \mathrm{~W} / \mathrm{m}^{2}$ into the system. (Please see Appendix A for further discussion).

As will be discussed in greater detail in the ensuing analysis, that $10 \mathrm{~m} / \mathrm{s}$ winds can impart between 0.05 and $0.1 \mathrm{~W} / \mathrm{m}^{2}$ into the system almost exactly correspond to the difference in dissipation observed between the $7 \mathrm{~m}$ and $5 \mathrm{~m}$ stations and the $5 \mathrm{~m}$ and $3 \mathrm{~m}$ stations during periods preceding the passage of cold fronts (where again, we are looking at the period of East to Southeasterly winds with wind gusts during energetic squalls exceeding $15 \mathrm{~m} / \mathrm{s}$ and sustained winds greater than $10 \mathrm{~m} / \mathrm{s})^{7}$.

\footnotetext{
${ }^{5}$ Mention is made in Appendix A of the non-default 1-D SWAN parameters employed.

${ }^{6}$ The empirical relations employed and their development is illustrated in the SWAN manual.

${ }^{7} \mathrm{~A}$ typical definition of a gust is as a sudden, brief increase wind speed, and according to common practice, gusts are when the peak wind speed reaches 16 knots $(8.2 \mathrm{~m} / \mathrm{s})$ and the variation in wind speed between the peaks and lulls is at least 9 knots $(4.6 \mathrm{~m} / \mathrm{s})$. Squalls are less precisely defined but are commonly though of as a sharp increase in short term wind speed (of longer duration than gusts) corresponding to an active weather pattern - such as the observed transitions from E, SE winds to $\mathrm{W}, \mathrm{NW}$ winds.
} 


\subsection{Analysis}

\subsubsection{Periods of Interest}
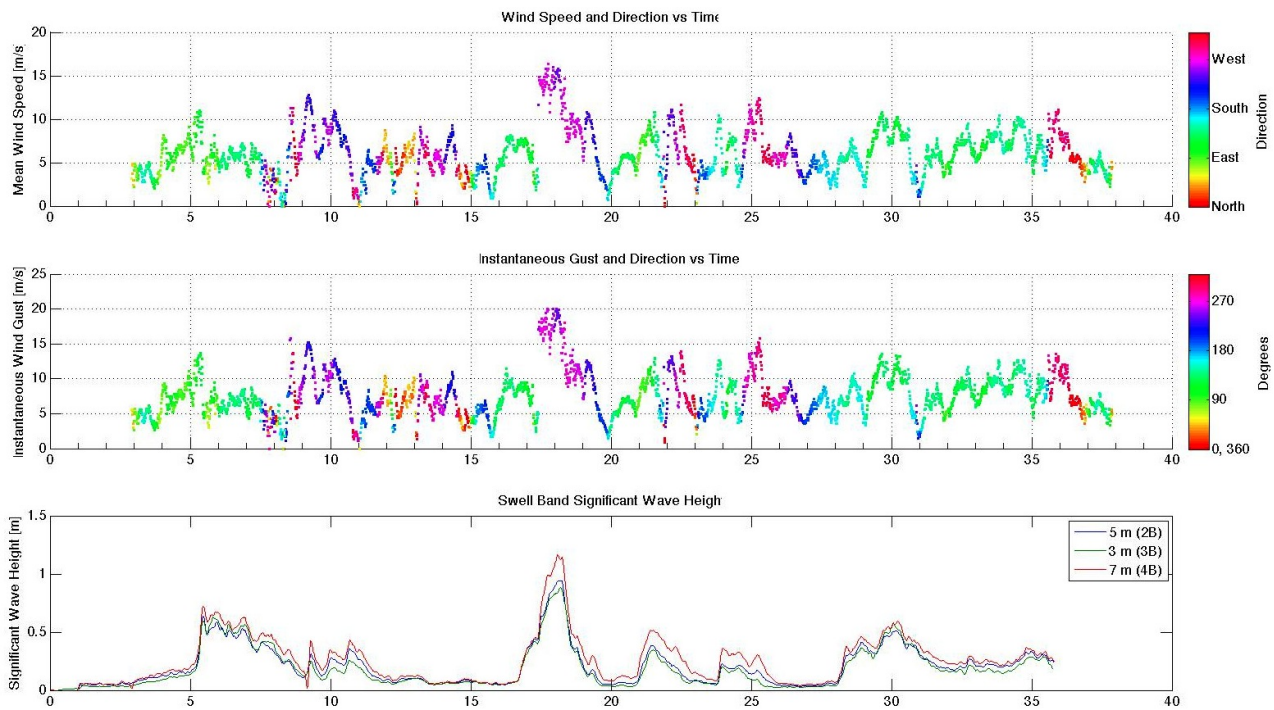

Figure 2-3: In the upper plot, mean wind speed and direction during the deployment window are presented. In the middle plot, bin maximum wind gust speeds and the directional data are presented. And in the bottom plot, swell-band significant wave height $\left(H_{\text {sig }}\right)$ at the three stations during the duration of the deployment. Wave height is in Blue, Green, and Red, for $3 \mathrm{~m}, 5 \mathrm{~m}$, and $7 \mathrm{~m}$ water depths respectively.

In analyzing the data from the deployment in March 2010, at least three separate cold fronts are clearly observed in wind speed and direction data. This is made obvious when looking at plots of the wind speed and swell-band significant wave height data presented in Figure 2-3, where there are wave height peaks and wind direction transition events between days 5 - 10, 15 - 20, and 25 - 30. Note the transition in each case is from East and Southeasterly winds $\left(90^{\circ}-135^{\circ}\right)$ to West and Northwesterly winds (predominantly $270^{\circ}$ to $315^{\circ}$ ) as briefly discussed in Section 2.1 .

As discussed previously in (Section 2.2.1), there are two periods of interest in these data sets where especially long, swell-band, shore-normal, flux divergence reversals are observed. What we will call 'period of interest 1' occurs between days 3 and 8 of the deployment, and similarly 'period of interest 2' occurs between days 28 and 33 of the deployment. 


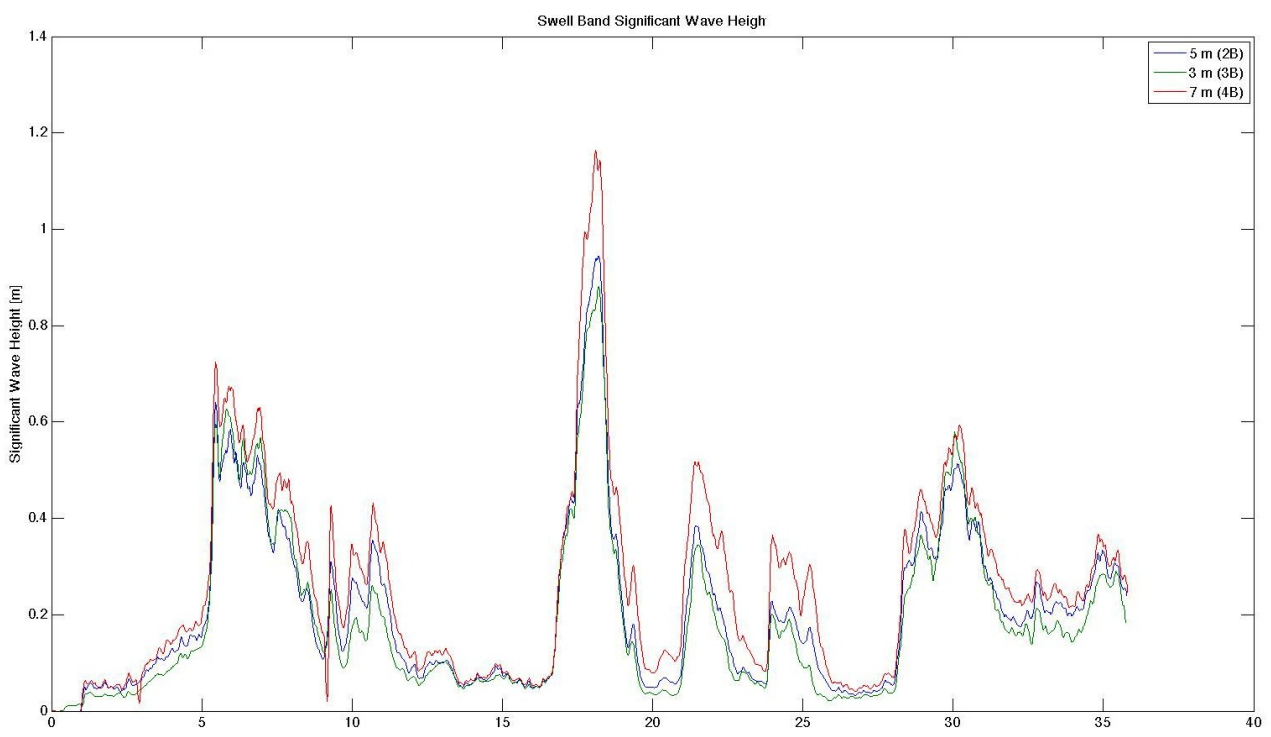

Figure 2-4: Swell-band significant wave height $\left(H_{\text {sig }}\right)$ at the three stations during the duration of the deployment. Wave height is in Blue, Green, and Red, for $3 \mathrm{~m}, 5 \mathrm{~m}$, and $7 \mathrm{~m}$ water depths respectively.

Although we will not discuss the largest event during this deployment, centered around day 17, our omission is strictly due to the flux divergence reversal not being as pronounced during the passage of that cold front. As can be clearly seen in Figure 24, there are peaks in swell-band significant wave height consistent with the wind data obtained from the same deployment windows but a significant flux divergence reversal does not develop.

\subsubsection{Acoustic Backscatter (ABS)}

As was discussed previously, all three instrumented stations seem to have been impacted by vessels more than once during the deployment, and although it was still possible to collect and parse pressure data from all three stations (from which wave spectra and fluxes were determined), acoustic backscatter sensors (ABS) were rendered partially inoperable. This is primarily due to the fact that once the stations had been impacted, in many cases, the acoustic sensors were no longer facing the sea-floor. As the ABS sensors had been deployed to indirectly measure thickness and density of the suspended sediment load and fluid mud layer this rendered much of 
their data effectively inscrutable. Specifically, the data from the $5 \mathrm{~m}$ and $7 \mathrm{~m}$ station ABS sensors will not be presented as it does not provide reasonable values during the periods of interest. In looking at the ABS data from the $3 \mathrm{~m}$ station during the periods of interest then, it should be noted that we are primarily concerned with determining if there was fluid mud present and if so, to what extent. It is primarily the presence or lack of fluid mud which allows the flux divergence reversal to develop since the system can potentially be situated to either side of the dissipation peak. Yet it bears repeating that from previous work with other datasets and in situ experience it is believed that the system is primarily to the right of the dissipation peak. This means that we are looking primarily at a regime where $\tilde{h}>1$ (or $h_{m u d}>\delta$, presuming we either back calculate kinematic viscosity from Kranenberg [2008], or from Winterwerp et al. [2007]).

\subsubsection{Error Analysis}

Determining a 'good' error estimate or threshold for the datasets presented herein is quite difficult. Specifically, as one is primarily limited to comparisons of aggregate or averaged values, external factors ${ }^{8}$ may have an outsized influence on the results when comparing theoretical and in situ quantities such as net energy flux or dissipation. These limitations may in part be due to short-term noise and variability in the signals, loss of useful data due to the instrumented stations being impacted, the erosion of the sediment around the footpad of the $3 \mathrm{~m}$ station, or any number of other factors.

Thus it is not particularly shocking to see that one of the error measures employed was of the same order of magnitude as the values calculated. Figure 2-5 depicts one measure of the error or confidence in the results discussed previously, by presenting the changes in shore-normal swell-band energy flux $(\Delta F$ in $\mathrm{W} / \mathrm{m})$ observed between stations for $7 \mathrm{~m}$ to $3 \mathrm{~m}, 7 \mathrm{~m}$ to $3 \mathrm{~m}$, and $5 \mathrm{~m}$ to $3 \mathrm{~m}$. Overlaid on each of the plots in Figure 2-5 is the mean standard deviation in energy flux between the two stations (also in $\mathrm{W} / \mathrm{m})$ calculated stepwise in time as $\left(\sigma_{F_{i}}+\sigma_{F_{j}}\right) / 2$ for $(i, j) \in\{(7,5),(7,3),(5,3)\}$

\footnotetext{
${ }^{8}$ External factors which may be difficult or impossible to model, and needless to say are beyond the scope of this work.
} 
over the duration of the deployment and then averaged.
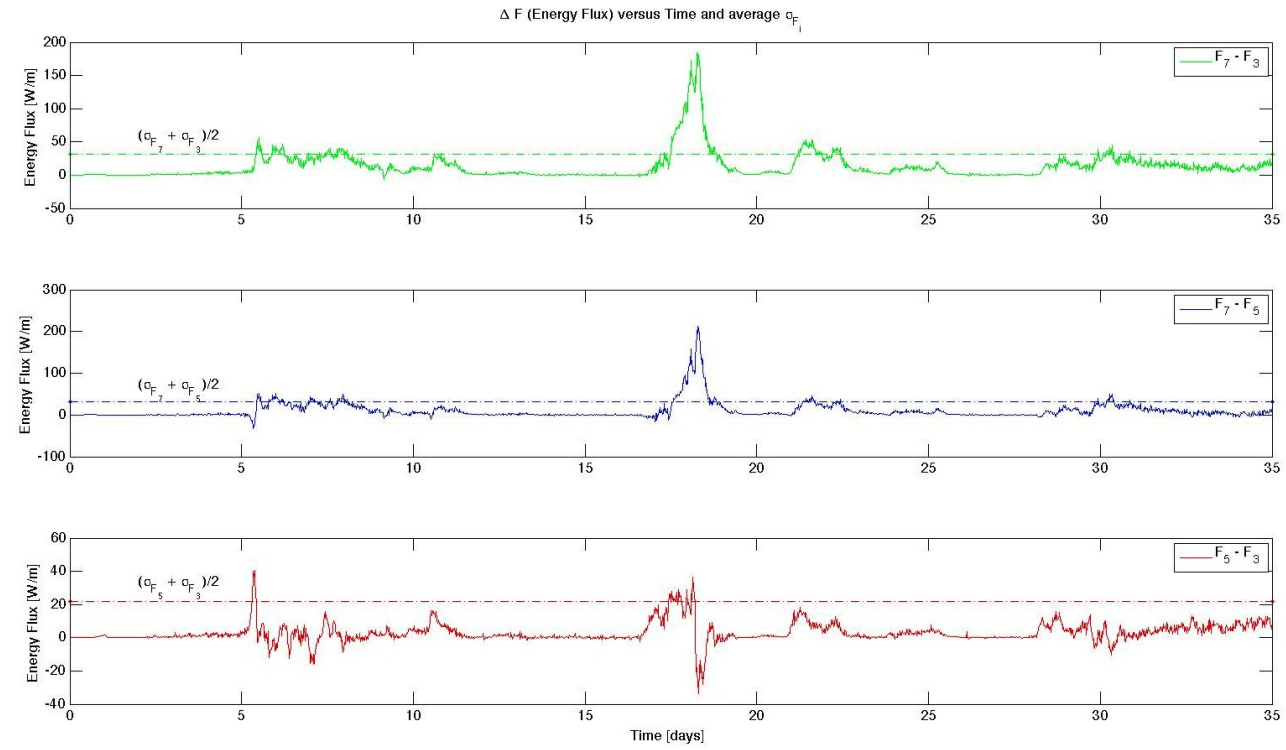

Figure 2-5: Three plots presenting the changes in energy flux $(\Delta F$ in $\mathrm{W} / \mathrm{m})$ between stations for $7 \mathrm{~m}$ to $3 \mathrm{~m}, 7 \mathrm{~m}$ to $3 \mathrm{~m}$, and $5 \mathrm{~m}$ to $3 \mathrm{~m}$. Overlaid on each plot is the mean standard deviation in flux between the two stations under consideration calculated over the duration of the deployment (also in $\mathrm{W} / \mathrm{m}$ ).

The first thing that bears noting in Figure 2-5 then, is that although the standard deviation in energy flux in the $7 \mathrm{~m}$ to $5 \mathrm{~m}$ segment of the array is approximately 1.5 times greater than that in the $5 \mathrm{~m}$ to $3 \mathrm{~m}$ segment, the corresponding ratio of array segment lengths is on the order of 1.7, implying that most if not all of the greater variability in the $7 \mathrm{~m}$ to $5 \mathrm{~m}$ segment's energy flux is a function of the increase in the physical distance between the sensors. Although a good portion of the energy flux signal in both independent segments is below the average variation in the signal does not invalidate or inherently contradict the conclusions arrived at previously. It merely bespeaks the need for further investigation of other datasets which will either lend further credence to the notion of a swell-band shore-normal flux divergence reversal or further underscore the effect that the large distance between sensors $(\Delta x)$ has on the calculated flux divergence $(d F / d x)$ in this dataset. Which in turn means that either the needed accuracy can not be achieved with the present setup or the signal separated sufficiently from the noise.

Another measure of error (or equivalently, the noise of the signals) in the data 

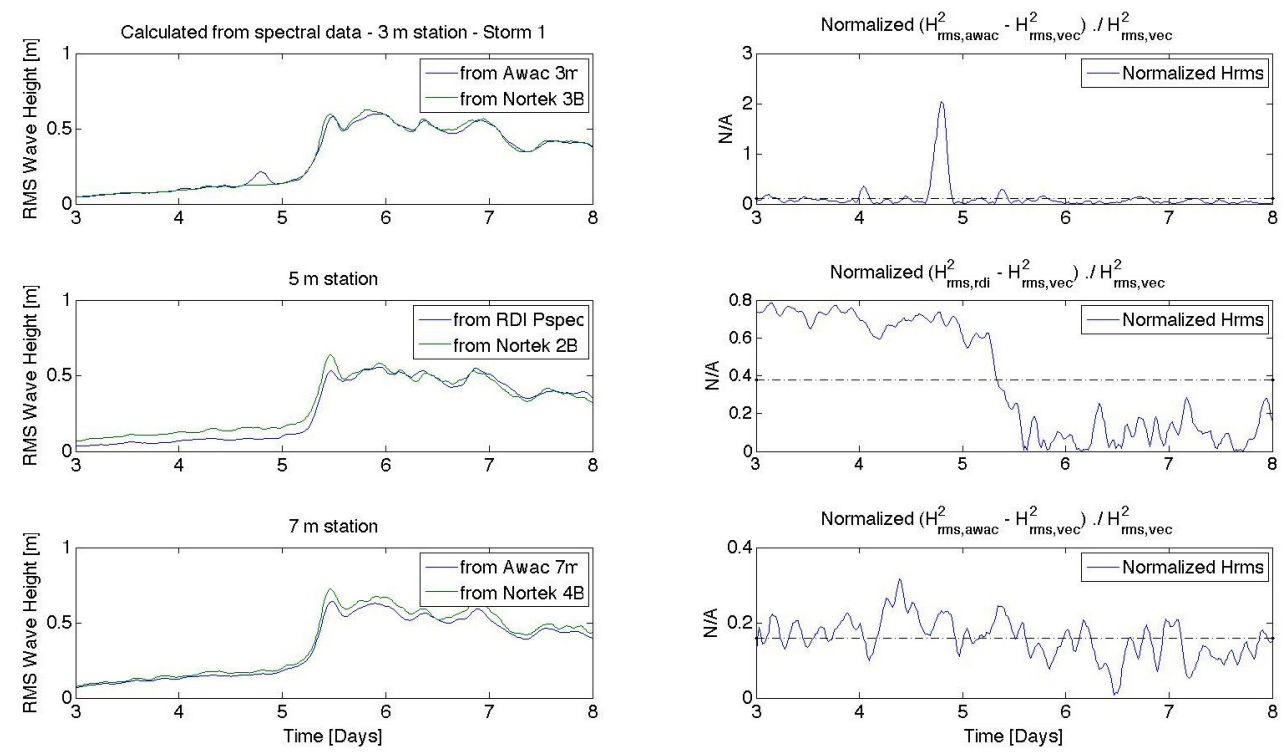

(a) Period of Interest 1 (Days 3 to 8 )
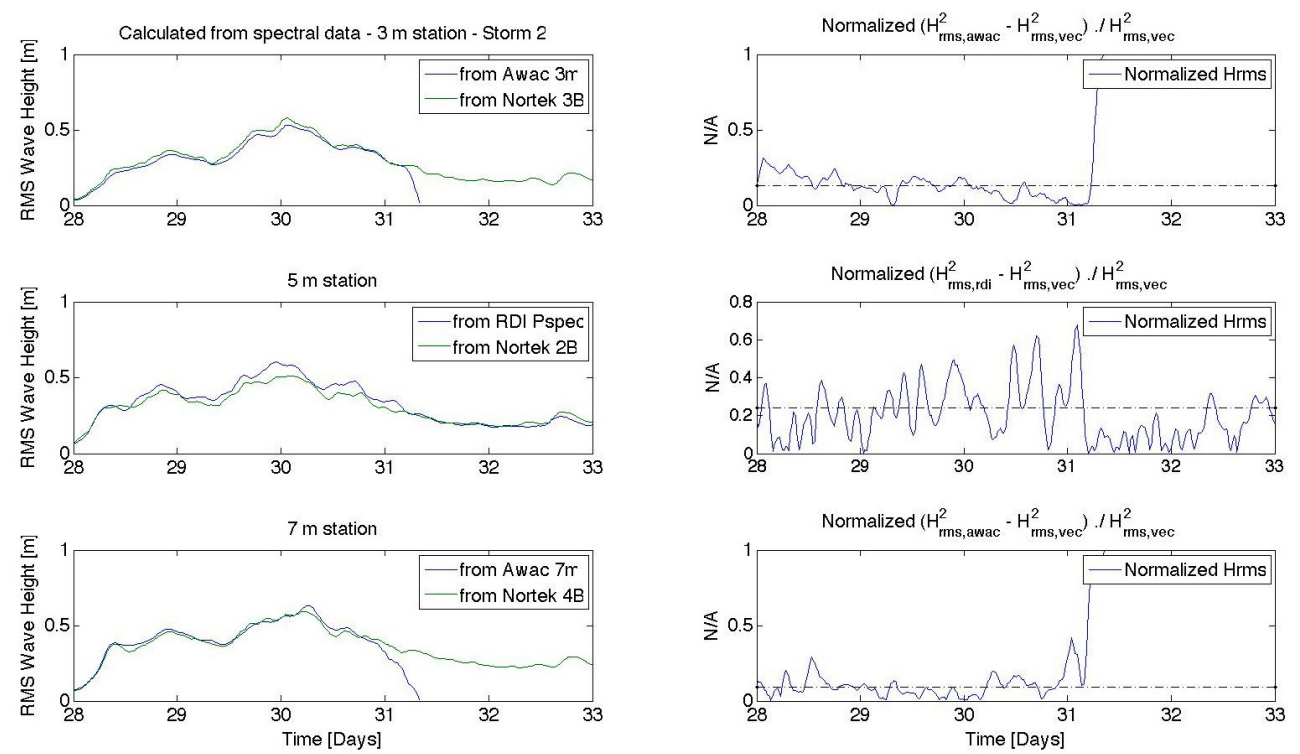

(b) Period of Interest 2 (Days 28 to 33 )

Figure 2-6: Comparisons of swell-band significant wave height during the two periods of interest. The right hand side plots all show measures of swell-band significant wave height $[\mathrm{m}]$, and then compare their normalized difference on the left hand side. The black dotted lines represent mean values for the windows plotted in each of the left hand side plots. 
would be a comparison against other datasets collected from other instruments deployed at the same stations which also had pressure sensors. Presented in Figure 2-6 are comparisons between two independent sensors at each of the three instrumented stations, wherein Figure 2-6(a) presents the comparison for the first period of interest (days 3 to 8 ), and Figure 2-6(b) for the second (days 28 to 33). As it was for the Nortek pressure sensors, wave height for the RDI and Awac sensors is calculated by integrating for the first spectral moment over the swell-band and then multiplying. It should be noted that for the second period of interest at the $3 \mathrm{~m}$ and $7 \mathrm{~m}$ stations, the second sensors being employed (Awac in the plots) ceased functioning around day 31, which accounts for the normalized error for those comparisons rising to one beyond that point. As such, for the second period of interest, the means presented as dotted black lines in Figure 2-6 are only calculated from days 28 to 31.

In looking at the dotted black lines in the plots of Figure 2-6, only one of the means even approaches 0.4 , and then only for the first period of interest. It seems to be due to a difference in the frequency band binning between the instruments under comparison during the low energy period between days 3 and 5.5. For the remainder of the stations for the two periods of interest the normalized difference between the signals is considerably less than 0.2 implying that the Nortek ADV pressure sensor data used throughout this thesis are consistent with other measures obtained during the same deployment. 


\section{Chapter 3}

\section{Results and Discussion}

\subsection{Discussion}

\subsubsection{Wind Input and SWAN}

Numerical calculations indicate that an incident wind forcing of $10 \mathrm{~m} / \mathrm{s}$ imparts between 0.05 and $0.1 \mathrm{~W} / \mathrm{m}^{2}$ into the system. Though, as the aforementioned conclusion is for calculations in the time domain, the $0.1 \mathrm{~W} / \mathrm{m}^{2}$ imparted to the system could be anywhere in the spectral domain and Figure 2-3 does not help us disambiguate the issue. Looking more closely at results of spectral modeling efforts (as in Figure 3-1), it becomes clear that the wind input only begins impinging on the spectral 'band of interest' - as demarcated by the bold portions of the curves in the plots.

Yet, as a standard JONSWAP spectrum was employed in these calculations, the interaction of the wind with the existent sea state in the Atchafalaya Bay may have been different than that modeled (the spectra for which is presented in Figure 2-2). This would mean that the wind observed in the Gulf may have had significantly different effects on the swell-band. One way this may occur when the energy transfer mechanisms at play in the Gulf are (at least temporally) more efficient than those parameterized in SWAN and are thus able effect the band of interest. Another potential method would be spatial variability along the array in the apparent bottom friction (as parameterized in SWAN) due to the presence or lack of fluid mud may 


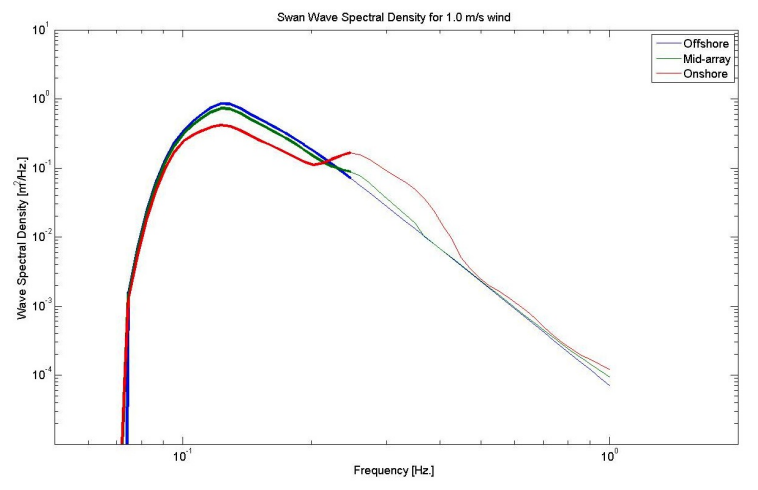

(a) $1 \mathrm{~m} / \mathrm{s}$ Wind Forcing

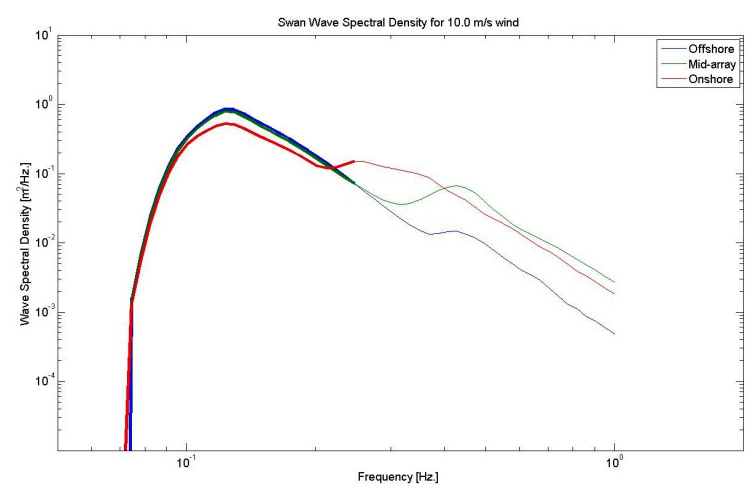

(c) $10 \mathrm{~m} / \mathrm{s}$ Wind Forcing

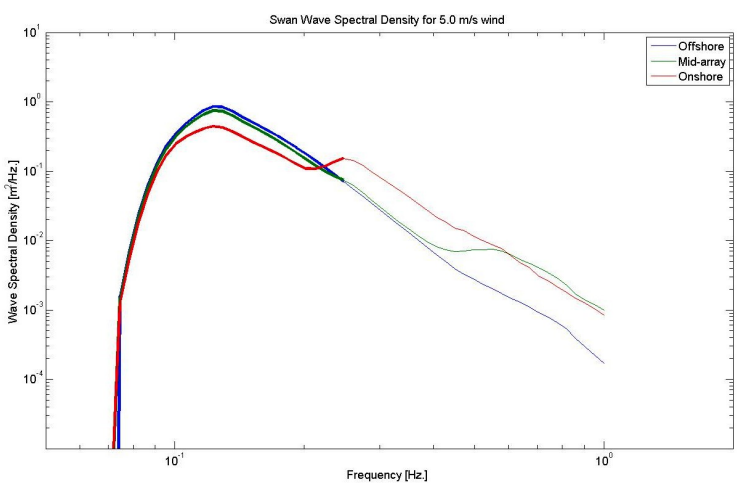

(b) $5 \mathrm{~m} / \mathrm{s}$ Wind Forcing

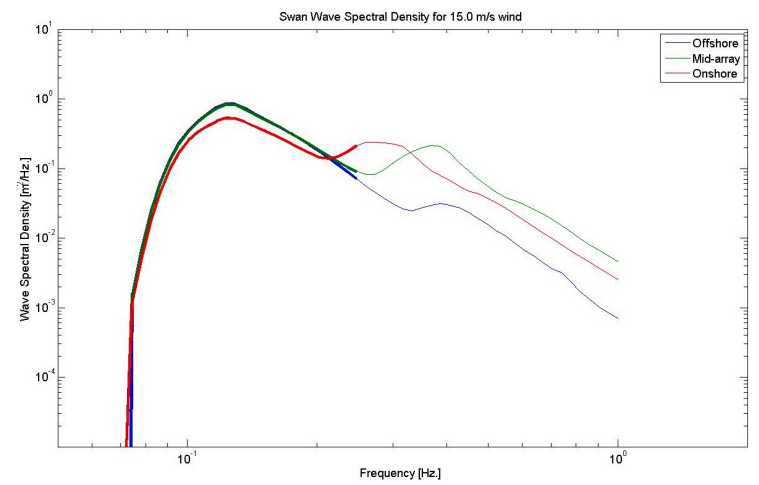

(d) $15 \mathrm{~m} / \mathrm{s}$ Wind Forcing

Figure 3-1: 1-D SWAN calculations for wave spectral density of a JONSWAP spectrum at three 'stations' along a $3 \mathrm{~km}$ array varying linearly in water depth from $7 \mathrm{~m}$ to $3 \mathrm{~m}$ with constant wind forcing as indicated. Note: the swell-band $(0.05 \mathrm{~Hz}$. to $0.2 \mathrm{~Hz}$.) is bolded in each curve of the above plots. 
play an outsized role in this.

Looking more closely into the second hypothesized method, that of changes in apparent bottom friction, Figure 3-2 presents a comparison of two sets of SWAN runs. In the first set, Figures 3-2(a) and 3-2(b), where the JONSWAP coefficient of friction (apparent bottom friction) was varied by an order of magnitude, and where non-linear triad interactions were disabled there does seem to be some onshore growth. But, it becomes clear from the second set of Figures 3-2(c) and 3-2(d), that without the nonlinear triad interactions, for either value of the coefficient, that the wind input does not enter the swell-band for the JONSWAP spectrum parameterized herein. Though, in allowing for the triad interactions there is an uptick in 'apparent' dissipation in the nearshore segment of the array, although it is not clear that it due to the wind, as the figures illustrate. But since the parameterization for the JONSWAP spectrum employed SWAN calculations is not the same as for the aforementioned spectrum (Figure 2-2), it becomes difficult to come to any firm conclusions

\subsubsection{Period of Interest 1}

For the first period of interest, between days 3 and 8, looking at Figure 3-3, one can clearly see the growth in the swell-band energy flux beginning at approximately day 5.5 of the deployment. This corresponds to a peak in significant wave height and squall wind speeds greater than $10 \mathrm{~m} / \mathrm{s}$. Additionally, the winds are consistently from the East to Southeast during the period of greatest observed flux divergence reversal (between days 5.5 and 7.5). A transition occurs around day 7.5, at which point the shore-normal swell-band energy flux has already begun to decrease. Now, looking at the swell-band flux divergence and dissipation, from Figure 3-4, it is clear that before day 5.5 there almost no shore-normal flux divergence. This is intuitive, as if there is no significant incident energy flux then the flux divergence will also presumably be negligible. But looking at the period between days 5.5 and 8 , we see a net $(7 \mathrm{~m}$ to $3 \mathrm{~m}$ - blue curve in Figure 3-4) positive flux divergence, which corresponds to an onshore decrease in energy and positive dissipation. Yet, the interesting phenomena is the reversal of flux divergence seen between the $5 \mathrm{~m}$ station and the $3 \mathrm{~m}$ station (red curve 


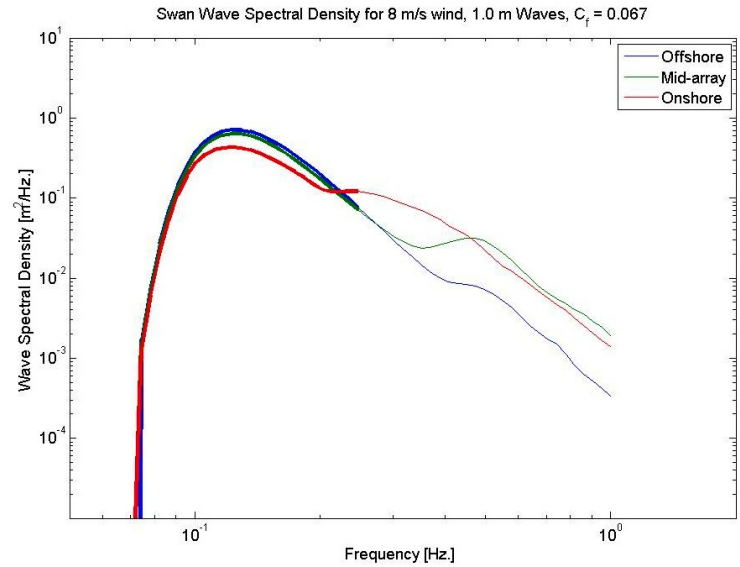

(a) JONSWAP Friction Coefficient: 0.067

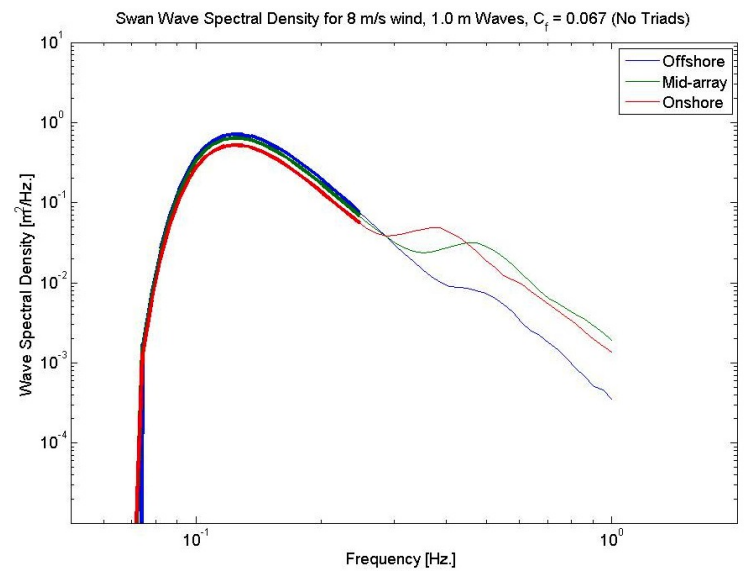

(c) JONSWAP Friction Coefficient: 0.067 Without triad interactions

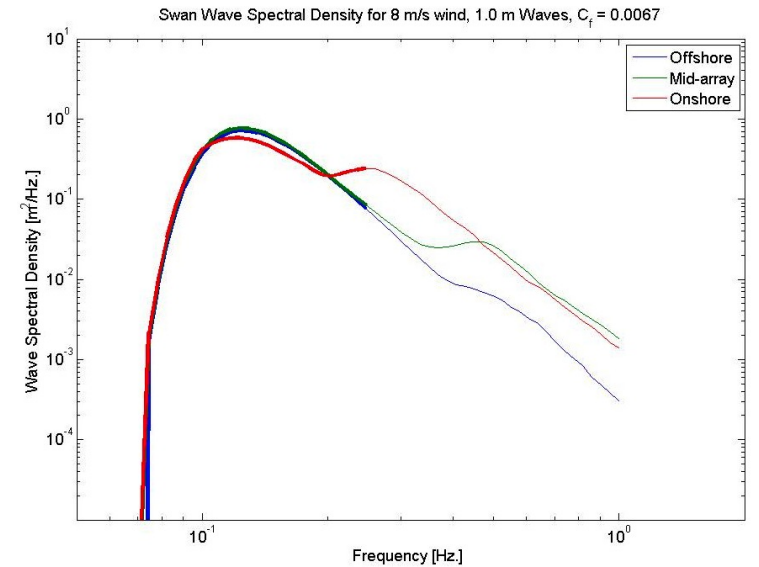

(b) JONSWAP Friction Coefficient: 0.0067

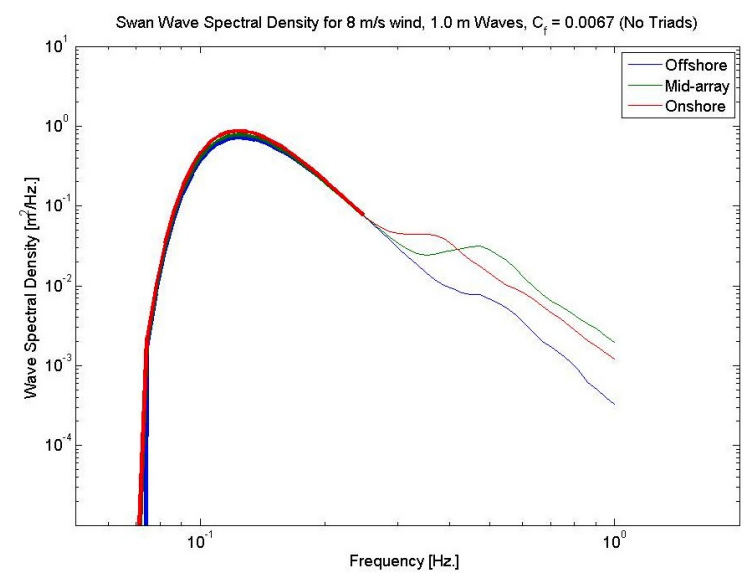

(d) JONSWAP Friction Coefficient: 0.0067 Without triad interaction

Figure 3-2: A comparison of 1-D SWAN calculations for $8 \mathrm{~m} / \mathrm{s}$ wind with $1 \mathrm{~m}$ waves, varying the JONSWAP friction coefficient between 0.067 and 0.0067 with and without non-linear triad interactions. 
in Figure 3-4). This corresponds to growth (i.e. addition or input of energy into the system) or at a minimum, no loss, as opposed to the $7 \mathrm{~m}$ to $5 \mathrm{~m}$ portion of the array where the flux divergence and dissipation are both positive.
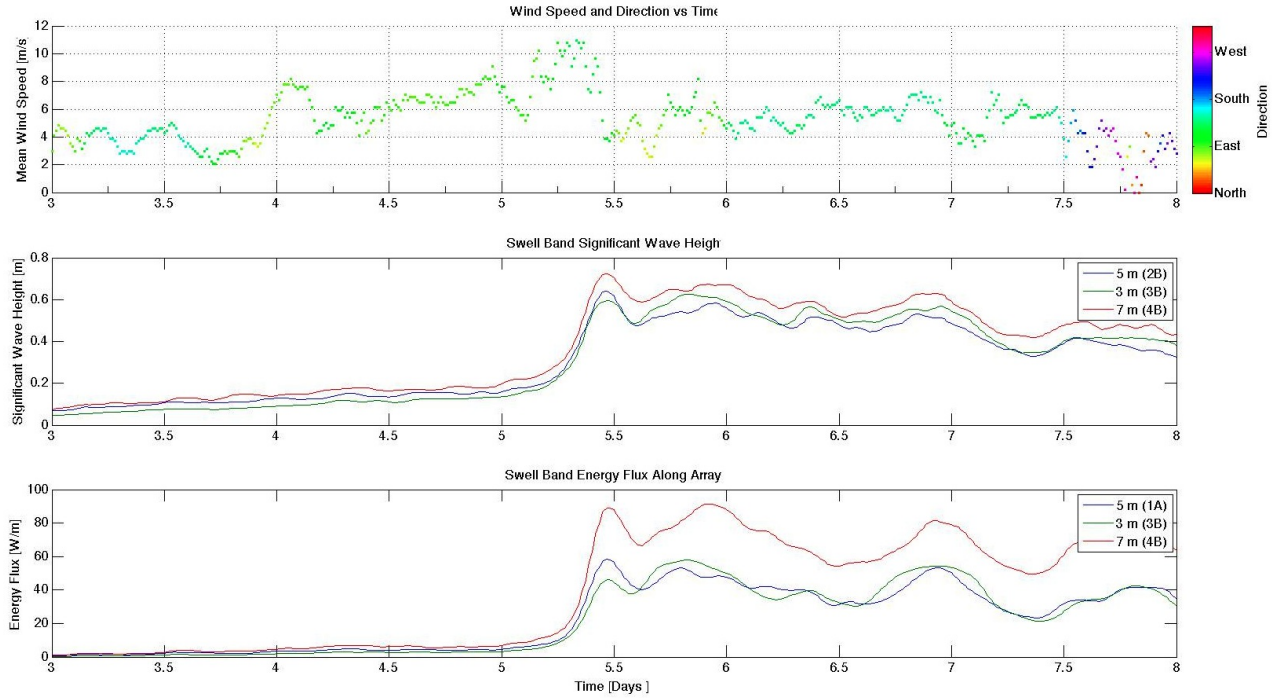

Figure 3-3: Mean wind speed and direction, swell-band significant wave height $\left(H_{\text {sig }}\right)$ and energy flux $(\mathrm{F})$ at the three stations during the first period of interest. Wave height and energy flux are in Blue, Green, and Red, for $3 \mathrm{~m}, 5 \mathrm{~m}$, and $7 \mathrm{~m}$ water depths respectively.

Now if we compare the calculated values for energy dissipation observed during the first period of interest (again, as seen in Figure 3-4) to the theoretical results discussed previously (and specifically in Figure 1-2), we see that the dissipation in the offshore array segment between the $7 \mathrm{~m}$ and $5 \mathrm{~m}$ stations hovers just below the peak observed in the theoretical model, implying that locally the viscous mud layer is approximately the same thickness as the Stokes boundary layer. In contrast, dissipation between the $5 \mathrm{~m}$ and $3 \mathrm{~m}$ stations is also initially right at the dissipation peak, and then transitions to a regime of energy growth (or accounting for potential error in the measurements, zero net dissipation), as is evinced by the negative values seen for $\mathrm{dF} / \mathrm{dx} / \mathrm{F}$ after day 5.5. This transition, and the energy input to the system after day 5.5 imply that the system is evolving away from that peak. It is thus clear that the local wave energy dissipation in the nearshore portion of the array can not be uniquely explained by wave damping due to a viscous lower layer and the cotemporal wind input and mud 

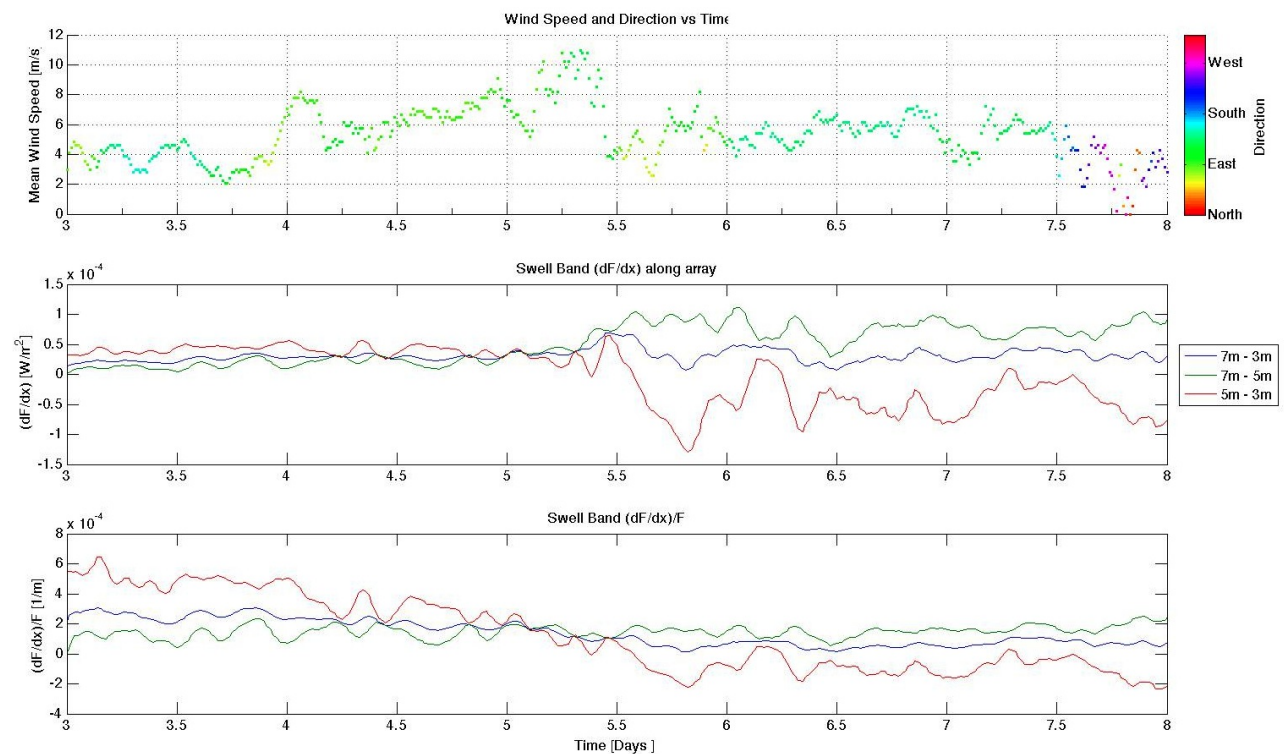

Figure 3-4: Mean wind speed and direction, swell-band flux divergence $(\mathrm{dF} / \mathrm{dx})$, and dissipation $(\mathrm{dF} / \mathrm{dx}) / \mathrm{F}$ during the first period of interest. Flux divergence and dissipation are in Blue, Green, and Red, for $7 \mathrm{~m}$ to $3 \mathrm{~m}, 7 \mathrm{~m}$ to $5 \mathrm{~m}$, and $5 \mathrm{~m}$ to $3 \mathrm{~m}$ respectively (as discussed in Section 2.2.1).

layer thickness must be considered.
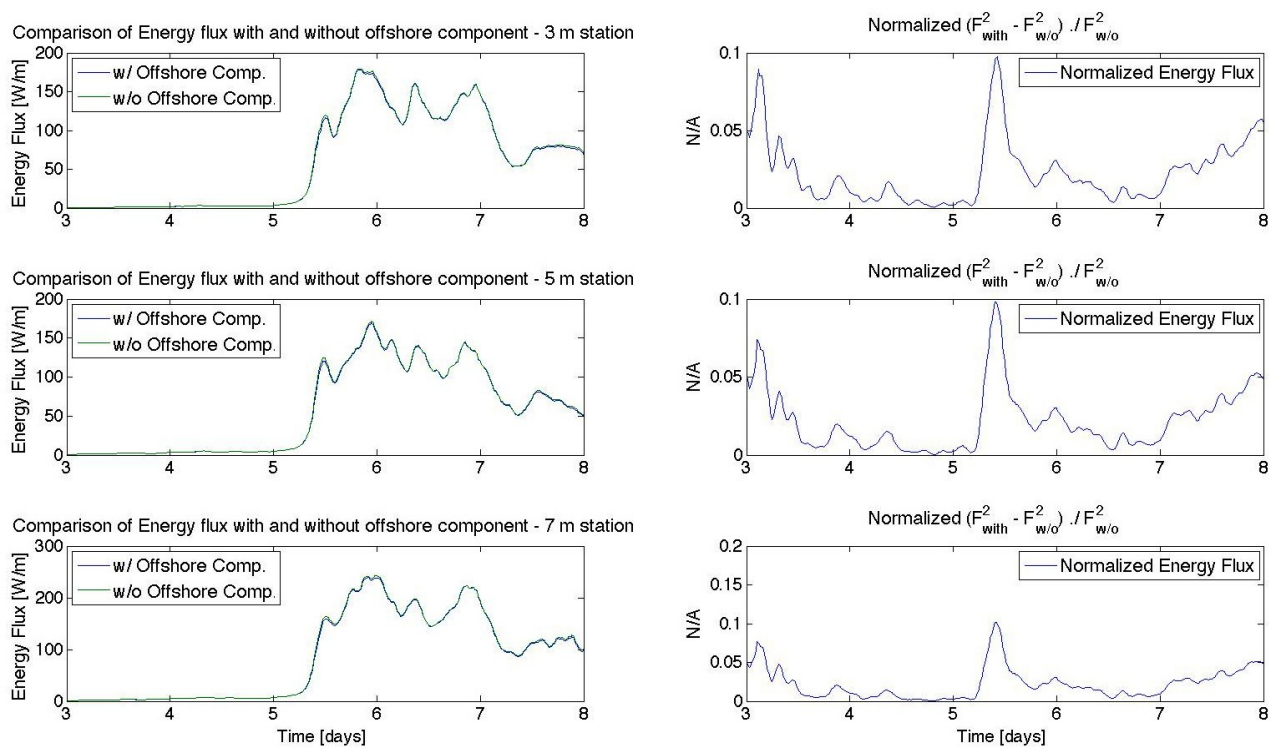

Figure 3-5: Comparison of swell-band energy flux for the three stations during days 3 to 8 with and without the offshore components of the directional spectrum.

It should be made clear, though, that what is being observed is not an offshore flux between the $5 \mathrm{~m}$ and $3 \mathrm{~m}$ stations accounting for the negative flux divergence (energy 
input), as all negative (offshore) components of the directional wave spectra have been set to zero in the aforementioned figures and analysis. Assuming that one can set all the offshore components of the spectrum to zero, this is verified by Figure 3-5 which compares the swell-band energy flux including the offshore components of the directional spectrum, and that without them. As can be clearly seen, at no point does the normalized difference between the energy flux with the offshore components and energy flux without it, rise above 0.1. It is thus clear that we are not seeing a flux divergence reversal due to an offshore flow of energy but one due to a decrease in dissipation or input of energy into the system. Additionally, as briefly mentioned earlier (and discussed in greater length in Appendix A), numerical calculations have shown that $10 \mathrm{~m} / \mathrm{s}$ winds can add between 0.05 and $0.1 \mathrm{~W} / \mathrm{m}^{2}$ into the system, although as currently parameterized the effects are not observed in the swell band.

\subsubsection{Period of Interest 2}

Turing now to look at the second period of interest, from days 28 to 33 of the deployment, where unlike the first period of interest when there was effectively no background swell-band energy flux before day 5.5, between days 28 and 29.5 there is non-negligible swell-band shore-normal energy flux (Figure 3-6). Yet, it is only after day 29.5 that the energy flux at the $3 \mathrm{~m}$ station exceeds that at the $5 \mathrm{~m}$ station. This again occurs for sustained winds of $10 \mathrm{~m} / \mathrm{s}$ with gusts greater than $15 \mathrm{~m} / \mathrm{s}$ as in the first period of interest. And again we see cotemporal reversals in flux divergence and energy growth (Figure 3-7). As with the first period of interest, we can show that this flux divergence reversal is not due to an offshore flow, but is due to energy input and decreased dissipation by comparing the energy flux with and without the offshore components of the directional spectrum (Figure 3-8). Although there are a number of peaks in the normalized difference between energy flux with and without the offshore components, over the duration of the second period of interest net offshore energy flux is negligible. Additionally, during the second period of interest, there is again a point at which the difference in flux divergences between the two segments of the array $\left(7 \mathrm{~m}\right.$ to $5 \mathrm{~m}$ and $5 \mathrm{~m}$ to $3 \mathrm{~m}$ ) is on the order of $0.1 \mathrm{~W} / \mathrm{m}^{2}$ (which is expected given 
the wind input to the system). This highlights the effect the interaction of sediment resuspension or fluid much motion and wind input can have on the system. It also serves to illustrate the dynamic nature and temporal variability of the phenomena under consideration, wherein the system can transition from the peak of the dissipation graph to one of the extrema within such a short timeframe.
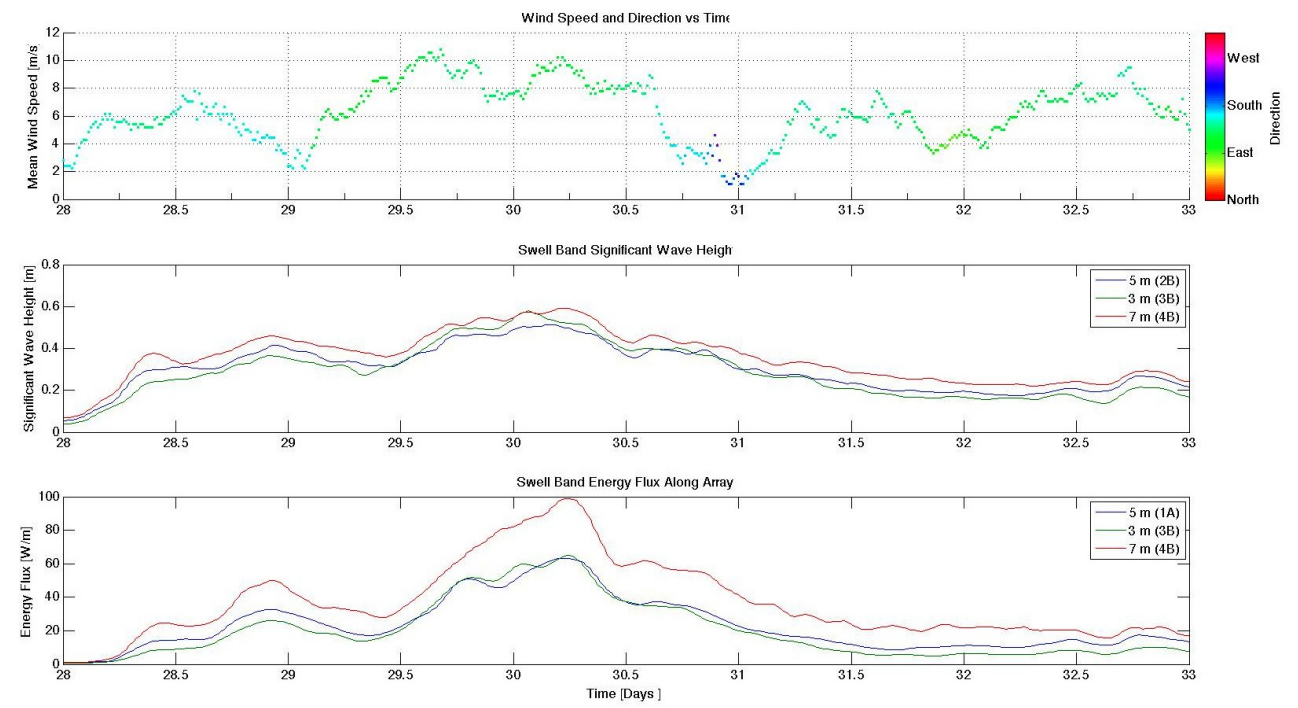

Figure 3-6: Mean wind speed and direction, swell-band significant wave height $\left(H_{\text {sig }}\right)$ and energy flux (F) at the three stations during the second period of interest. Wave height and energy flux are in Blue, Green, and Red, for 3m, 5m, and $7 \mathrm{~m}$ water depths respectively.

Again comparing the theoretical values of energy dissipation as discussed in Section 1.2 to those observed during the second period of interest (Figure 3-7), we see that the dissipation between the $7 \mathrm{~m}$ and $5 \mathrm{~m}$ stations seems to hover around the theoretical peak but that the observed dissipation in the nearshore component of the array seems to deviate from the offshore component at around day 29.5 of the deployment. Then it rather dramatically turns negative. This indicates swell-band wave energy growth at that time. And again, this energy input must be due to external forcing as only when the system is far away from the theoretical peak (of $\tilde{h} \approx 1$ ) either due to a lack $(\tilde{h}>>1)$ or abundance of mud $(\tilde{h}<<1)$ and a concurrent strong wind pattern will the wind input be observed to effect the dissipation data. 

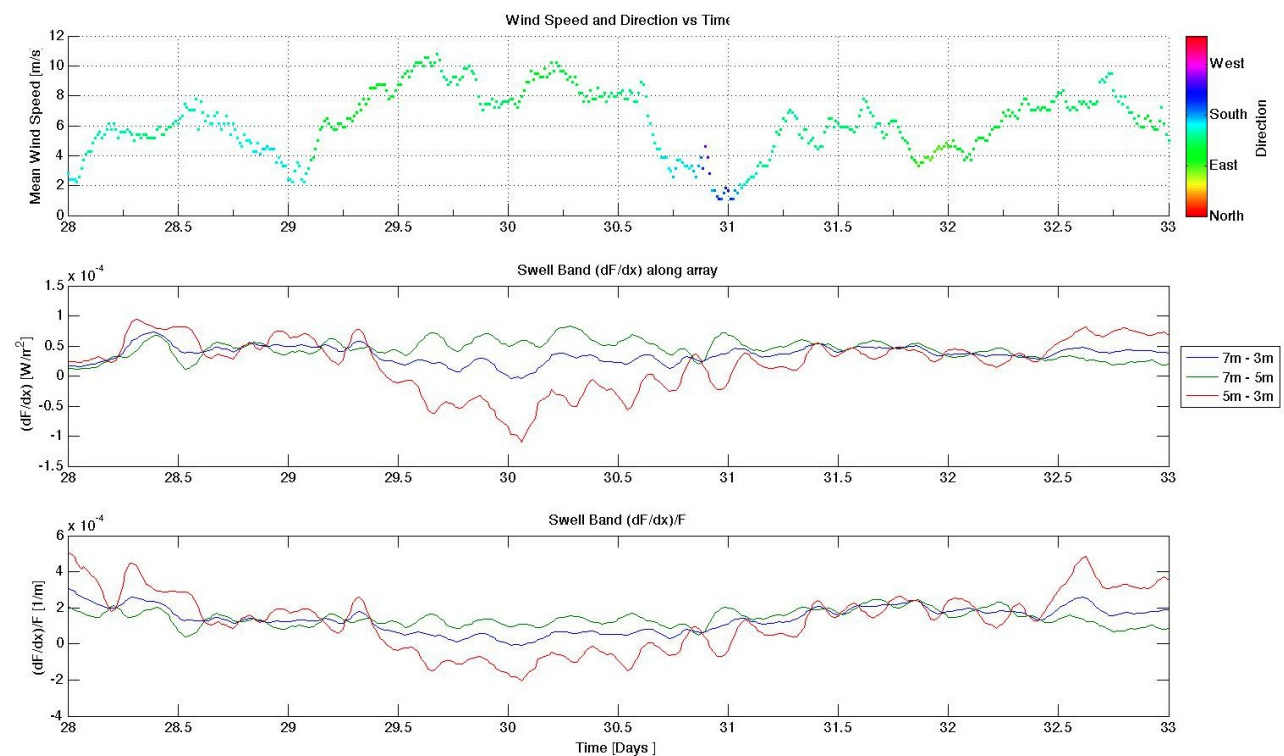

Figure 3-7: Mean wind speed and direction, swell-band flux divergence ( $\mathrm{dF} / \mathrm{dx})$, and dissipation $(\mathrm{dF} / \mathrm{dx}) / \mathrm{F}$ during the second period of interest. Flux divergence and dissipation are in Blue, Green, and Red, for $7 \mathrm{~m}$ to $3 \mathrm{~m}, 7 \mathrm{~m}$ to $5 \mathrm{~m}$, and $5 \mathrm{~m}$ to $3 \mathrm{~m}$ respectively.
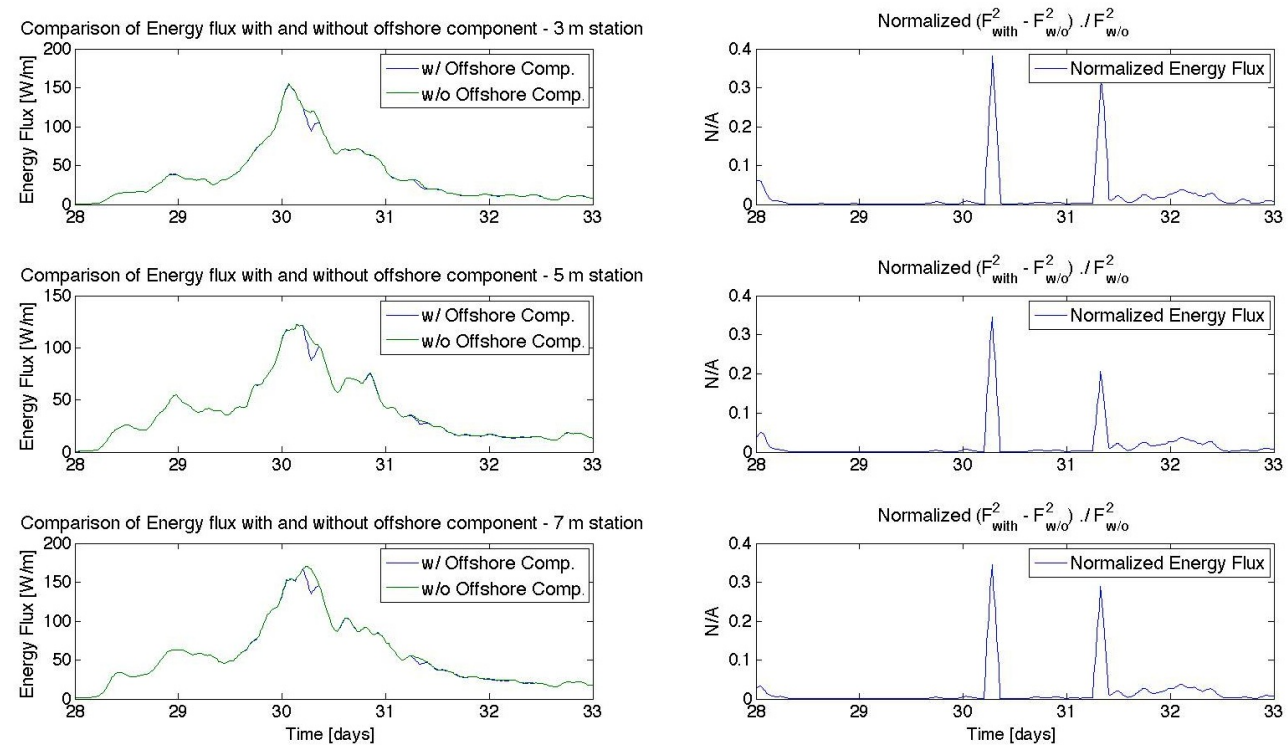

Figure 3-8: Comparison of swell-band energy flux for the three stations during days 28 to 33 with and without the offshore components of the directional spectrum.

\subsubsection{Burst Averaged ABS data}

In looking at the burst averaged ABS data (presented for the $3 \mathrm{~m}$ station in Figure 39), the reds and yellows in the pseudocolor plots represent the highest ABS intensity, 

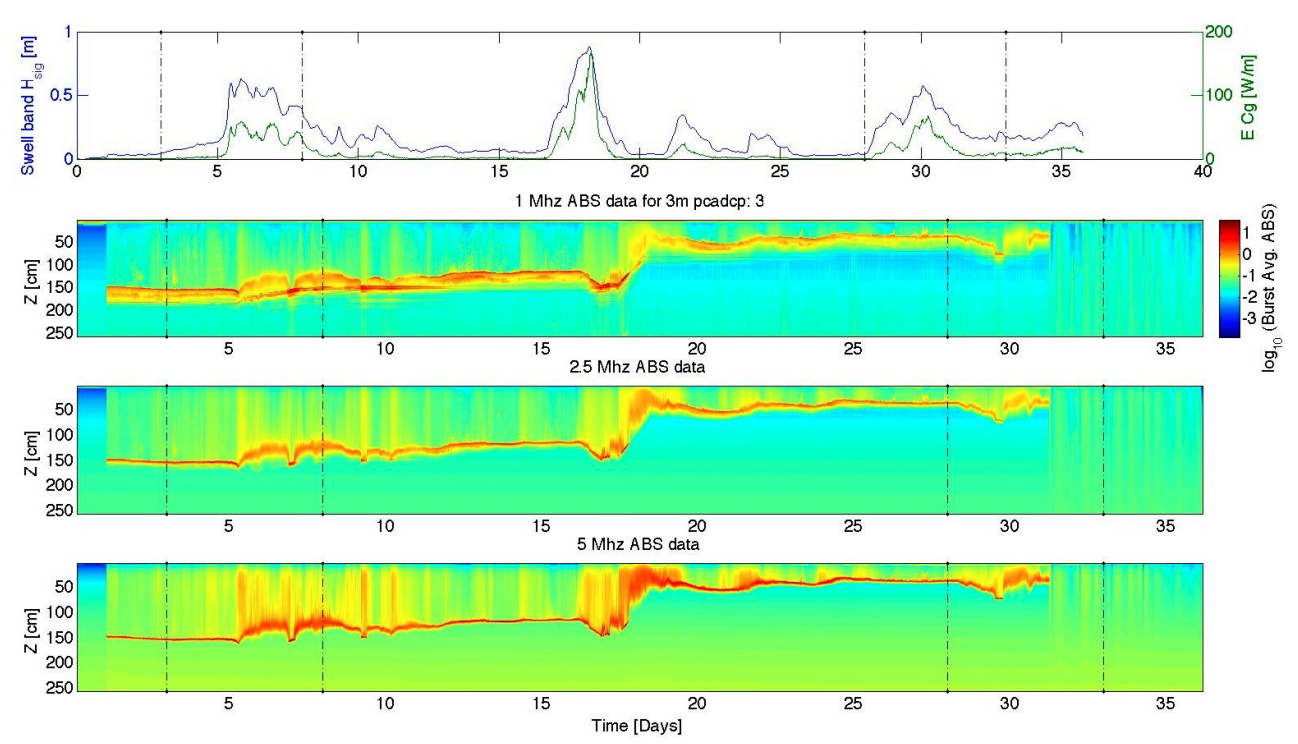

Figure 3-9: Significant wave height $[\mathrm{m}]$, energy flux $[\mathrm{W} / \mathrm{m}]$, and burst averaged ABS data from the $3 \mathrm{~m}$ station during the duration of the deployment. The three pseudocolor plots are for the $1 \mathrm{Mhz}, 2.5 \mathrm{Mhz}$. and $5 \mathrm{Mhz}$. ABS data. The black dot dashed lines represent the extent of the periods of interest from days 3 to 8 and 28 to 33 of the deployment, as defined previously.

and thus depict the consolidated bottom or the top of the fluid mud layer. Yellows are a 'denser' suspended sediments which are in the water column, and are not as dense as a fluid mud ${ }^{1}$. Similarly, greens or blues above the red line (consolidated bottom) would correspond to the water column and minimal additional sediment load.

From the ABS data it is clear that concurrent with the flux divergence reversal during the first period of interest, there is significant suspended sediment and fluid mud present at the $3 \mathrm{~m}$ station (days 5.5 to 8 in Figure $3-4$ ). This can be seen in the burst averaged ABS data when looking at Figure 3-9, between days 5.5 and 9.5, where there is a very clear uptick in the suspended sediment load.

To digress briefly, as can be seen between days 17 and 20 in the $3 \mathrm{~m}$ burst averaged ABS data (Figure 3-9), there is a significant observed rise in the sea-bed of almost a meter. This is not thought to be completely physical. It is hypothesized that either erosion around the footpad of the station led to the tripod sinking relative to the mudwater interface or that this was one of the times the $5 \mathrm{~m}$ station was impacted by a vessel and subsequently resettled. Although, the strong storm observed between says

\footnotetext{
${ }^{1}$ Where fluid mud is defined as having densities $\geq 10 \mathrm{~g} / \mathrm{L}$ of sediment [Kineke et al., 1996].
} 
17 and 20 of the deployment, which is evident from the significant wave height and energy flux data, could potentially account for at least some of the growth observed during that time frame.

Returning for a moment to the discussion of the peak in imaginary wave number and in particular Figure 1-2 in Section 1.2, it is clear that during the first period of interest, at least from day 5.5 onward at the $3 \mathrm{~m}$ station, the system is closer to the right hand side of the plot portraying imaginary wavenumber versus normalized mud layer thickness as the mud is 'thick' and its kinematic viscosity is relatively low. Analysis of the burst averaged ABS data shows that there is significant suspended sediment and fluid mud present and Figure 3-3 shows that there is energy growth observed during this period.

The burst averaged ABS data from the second period of interest, days 28 to 33, does not present as convincing a picture as it does for the first period of interest. One reason is that the $3 \mathrm{~m}$ data abruptly ends at around day 31 , due to what can only be presumed to have been a vessel impact of the station. Yet, before that, between days 28 and 31 the thickness of the layer does not appear to be as significantly different from the Stokes boundary layer thickness as it did during the first period of interest. Therefore, any conclusions derived regarding the relative magnitude of the normalized mud layer thickness, and therefore the influence of the cold-fronts passage on sediment resuspension or motion would be tenuous at best.

\subsubsection{ABS Burst data}

Now, considering a set of individual 1 Mhz. ABS bursts from the $3 \mathrm{~m}$ station during the first period of interest (as shown in Figure 3-10), one can begin to think about not only the mud layer thickness, but also the associated lutocline (fluid mud - water interface) wave. Recalling that during the first period of interest there is minimal swell-band flux divergence until day 5.5 of the dataset, since there is minimal swellband energy flux observed between days 3 and 5.5 (as seen in Figure 3-4). The ABS burst data from the $3 \mathrm{~m}$ station seems to validate this conclusion, as during the first two days of the first period of interest there is very little activity on the interface, but 
between days 5 and 6 of the deployment (between March 8th and 9th in Figure 3-10) one sees the development of a $50 \mathrm{~cm}$ interfacial wave. If one considers the ABS burst averaged data and the associated thickness of the fluid mud observed (presented in Section 3.1.4 and Figure 3-9), this implies that the amplitude of the mud-water wave observed is of the same order of magnitude as the layer thickness.

Fluctuations on the lutocline during the period after day 5.5 in Figure 3-10, could indicate enhanced damping at the $3 \mathrm{~m}$ station during this period. This would be inconsistent with the hypothesis that flux divergence is reduced in shallow water during the periods of interest, yet measures of flux divergence and dissipation developed for the first period of interest (Section 3.1.2) still show that this is potentially occurring. One possible explanation would be that there is a temporal changes in the depth dependence of the flux divergence due to the balance of the different sources and sinks of energy present but further analysis, and velocity profiles would be required to understand the apparent inconsistency between the ABS data and the temporal changes characterized earlier.

Similarly, when looking at Figure 3-11 in reference to the flux divergence observed between days 28 and 33 of the deployment, (the second period of interest - Figure 3-7) one can clearly see the growth and decay of the mud-water interfacial wave as time progresses through the first four plots of the figure. The fifth plot in Figure 3-11 was included to again illustrate the abrupt cutoff observed in the datasets for most of the sensors at around day 31 and the challenges thus posed.

\subsection{Results}

In an attempt to collate the different analyses and datasets presented heretofore, Figures 3-12 and 3-13 are essential recreations of those in Section 2.3.1 including the measures of uncertainty developed in Section 2.3.3. The colored bands are in effect plus or minus one standard deviation around the calculated values. Thus, for Figure 3-13 it becomes easier to discern when the claim of a swell-band shore-normal flux divergence reversal is potentially statistically significant, first in comparison to 


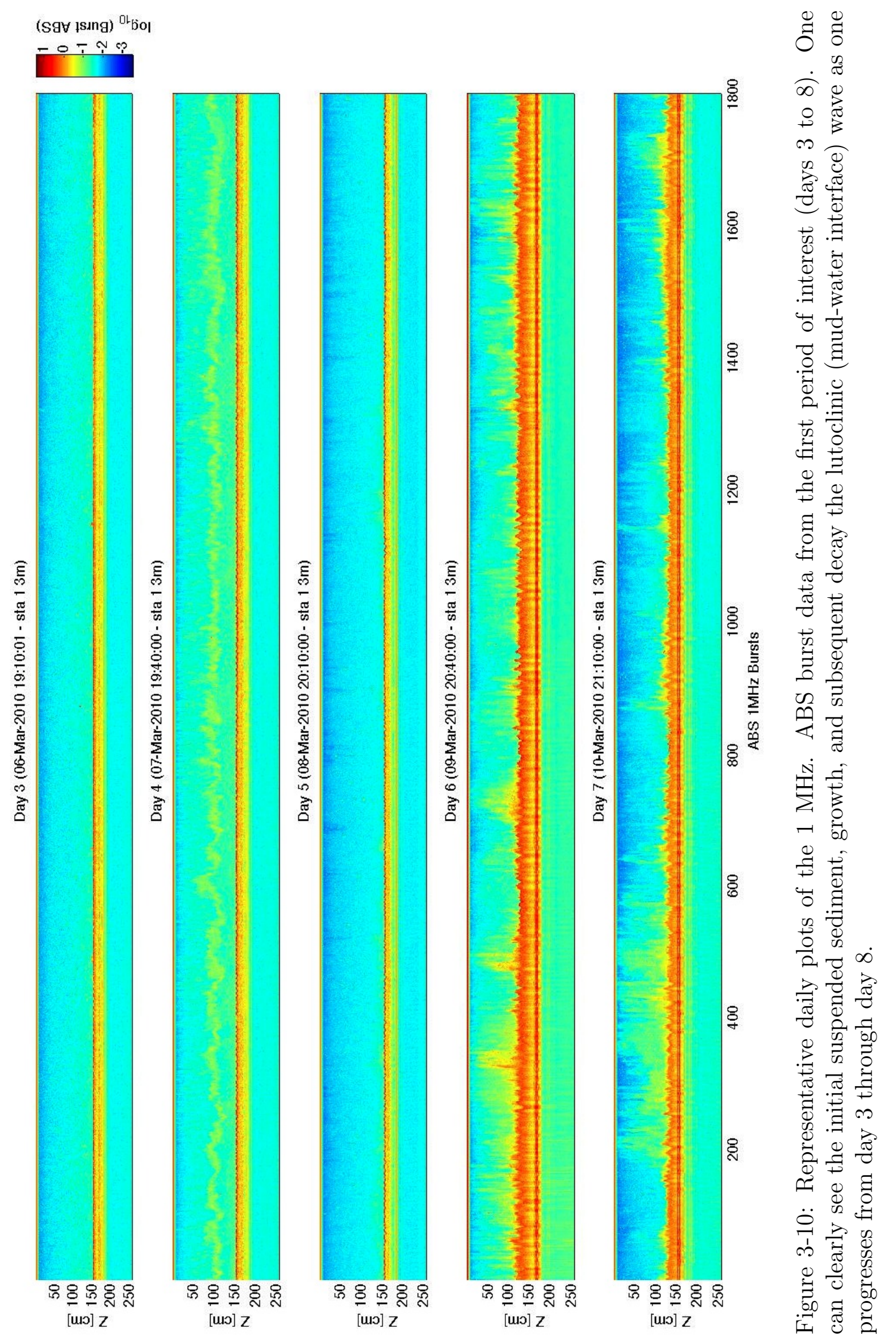




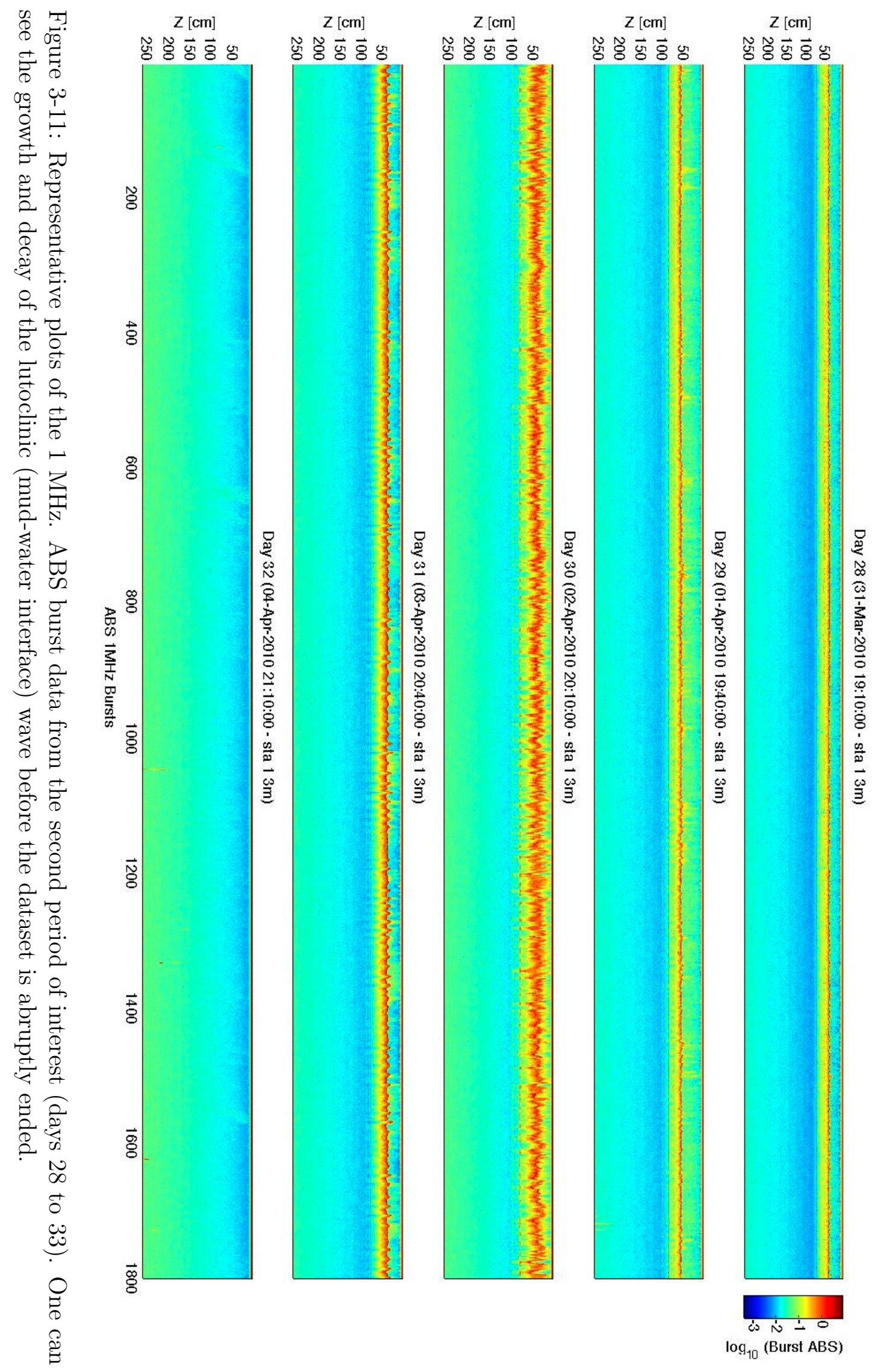


the other sensor segment and then if it is different from zero.

As it is clear from the plots that although there is a significant difference between the flux divergence (or dissipation) in the $7 \mathrm{~m}$ to $5 \mathrm{~m}$ section as opposed to in the $5 \mathrm{~m}$ to $3 \mathrm{~m}$ section, it is not clear that the term reversal can be used as unambiguously as thought earlier. Having now looked at measures of error, a better explanation may be that a local balancing between the wind forcing and bottom induced dissipation due to the presence of fluid mud took place. From SWAN model calculations presented earlier, it is clear that the wind input only impacted the swell-band portion of the wave spectral density at the upper end of the band of interest, even at up to $15 \mathrm{~m} / \mathrm{s}$ forcing. Yet, if one looks at similar SWAN calculations when varying the model's bottom friction parameter - which can act as a proxy for the presence or lack of fluid mud - as in Figure 3-2 one observes that when there is less bottom friction present, one sees the wind input impinging more heavily in the band of interest.

These conclusions would seem to imply that given a local dearth of fluid mud, a swell-band shore-normal may exist, but that the results presented in this thesis for the March-April 2010 Atchafalaya Bay deployment may turn out to be inconclusive on this count, but that does not mean that the mechanism proposed is neither feasible nor present. As it is clear that at a minimum, there is a local balance developed between energy input and energy dissipation. Whether that develops into a reversal remains speculative. 

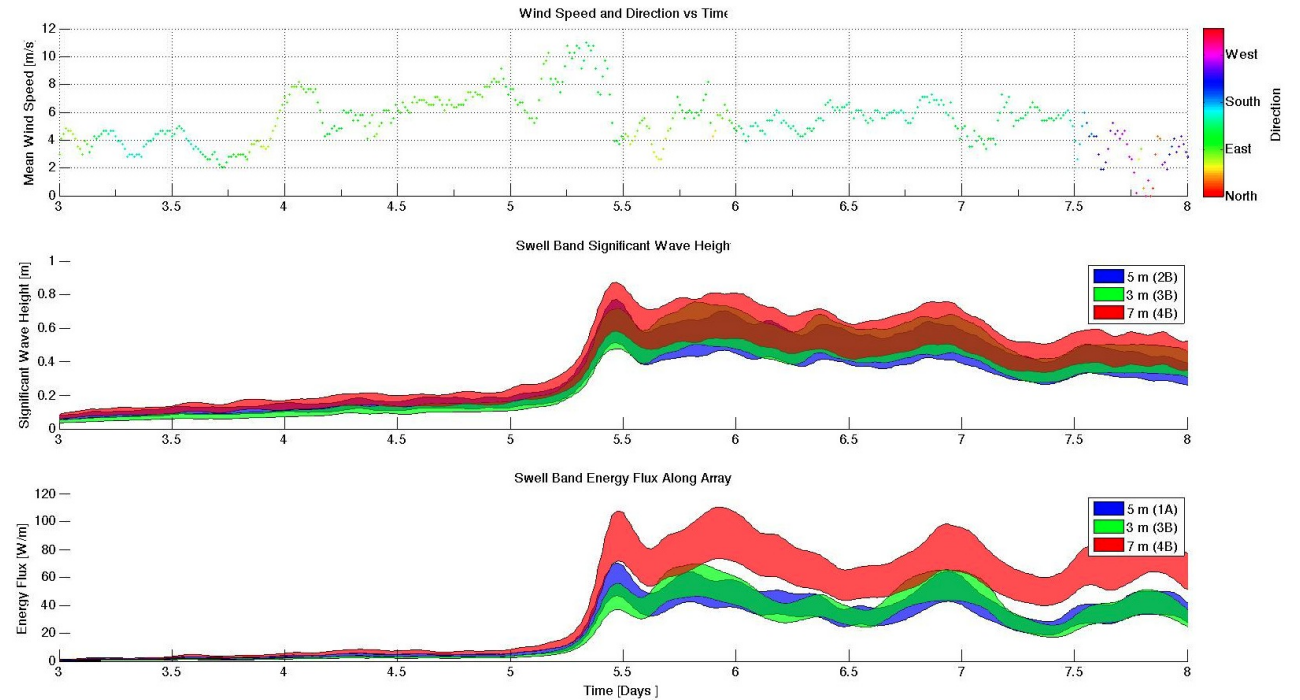

(a) Period of Interest 1 (Days 3 to 8)
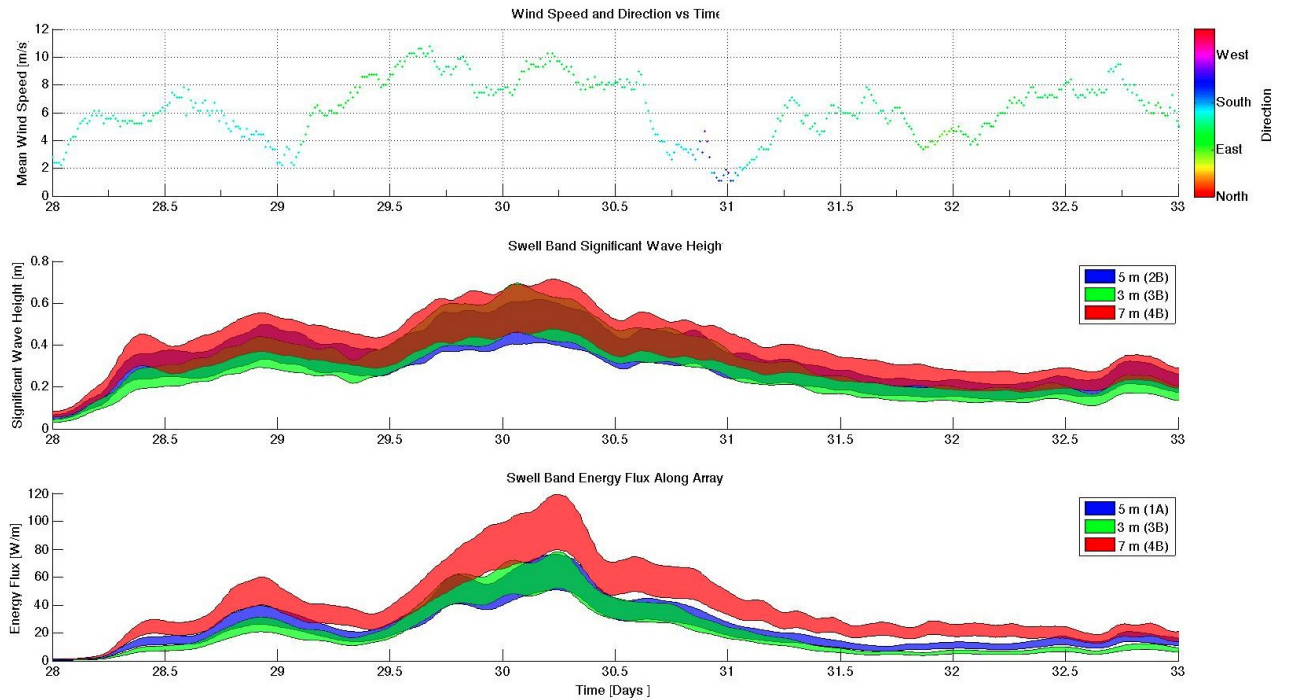

(b) Period of Interest 2 (Days 28 to 33 )

Figure 3-12: Wind speed, swell-band significant wave height, and energy flux during the two periods of interest. The significant wave height and energy flux are plotted as to illustrate the bands of uncertainty in the calculated values presented (via the errors discussed previously). 

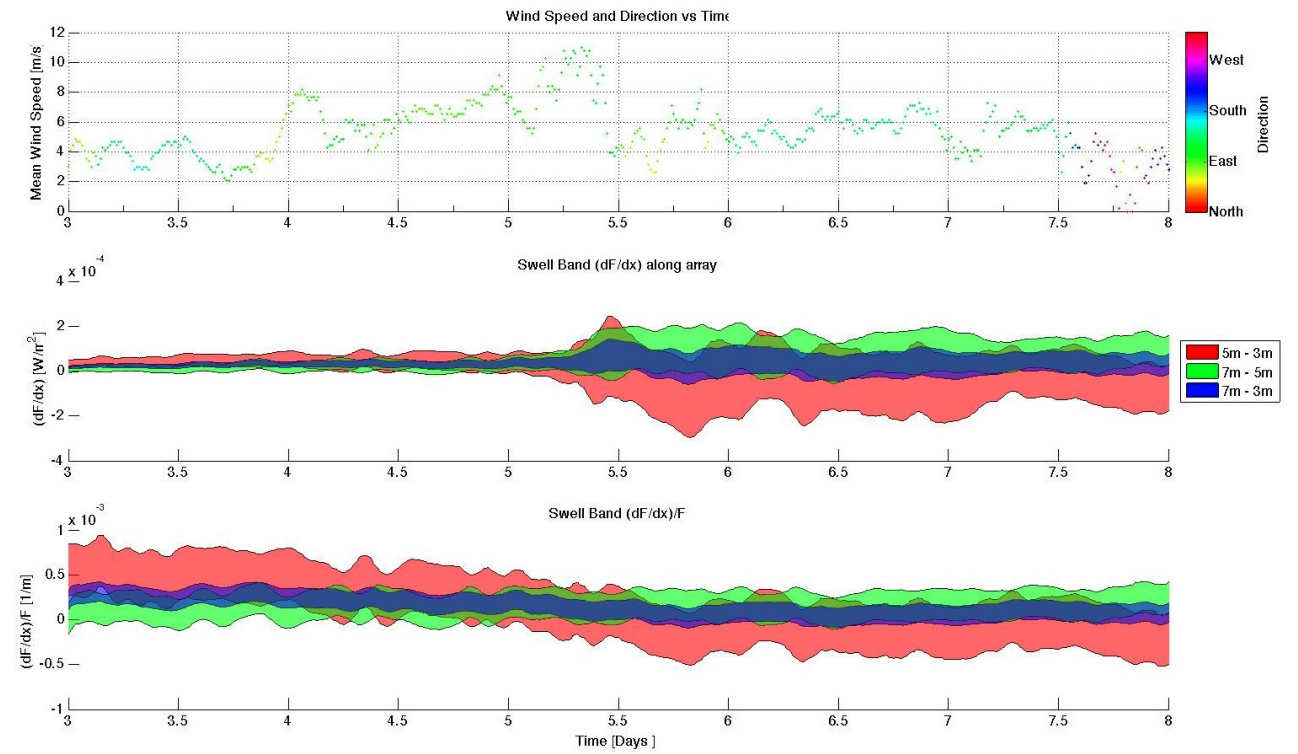

(a) Period of Interest 1 (Days 3 to 8 )
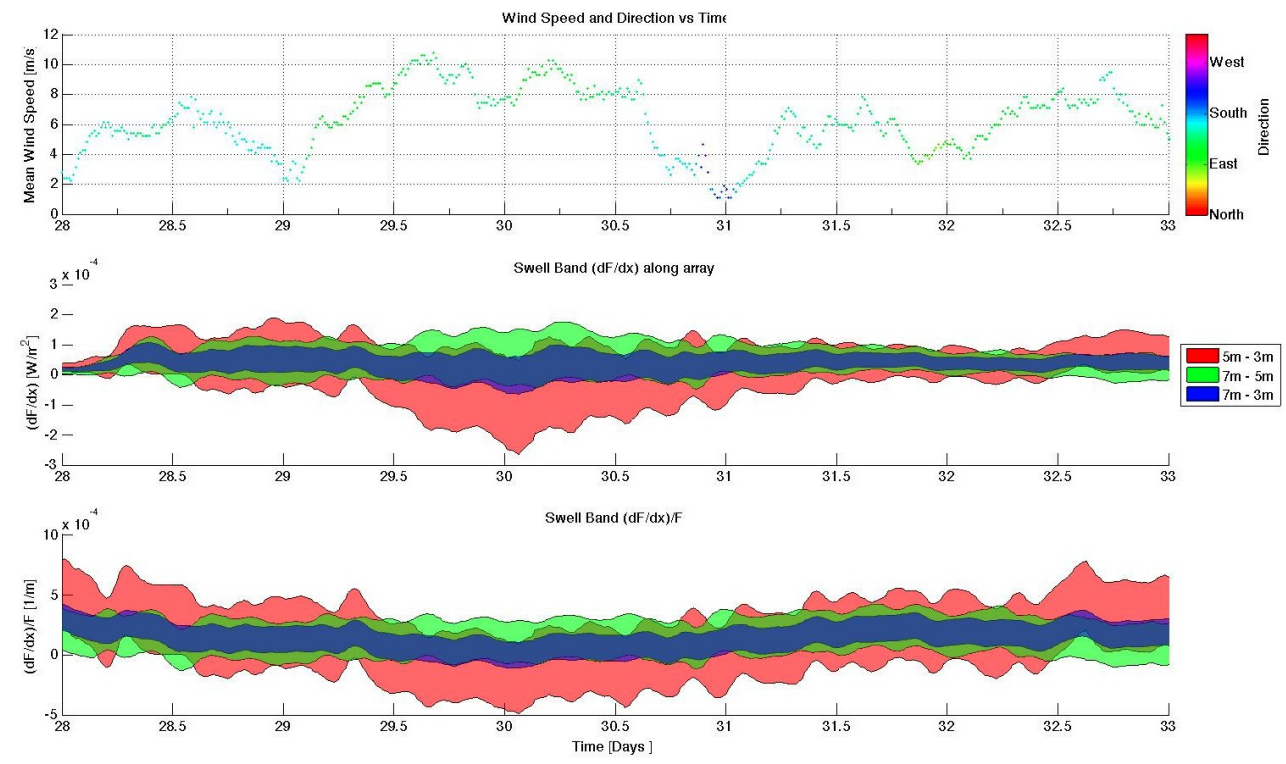

(b) Period of Interest 2 (Days 28 to 33 )

Figure 3-13: Wind speed, swell-band flux divergence, and dissipation during the two periods of interest. The flux divergence and dissipation are plotted as to illustrate the bands of uncertainty in the calculated values presented (in a similar manner to those calculated in Figure 3-12). 


\section{Chapter 4}

\section{Conclusions}

The analysis presented in this thesis has examined the hypothesis that a shore-normal swell-band energy flux divergence reversal existed and persisted across multiple coldfronts during a deployment in the Atchafalaya Bay, Gulf of Mexico, during MarchApril 2010. It has done so via a combination of data analysis, comparison against theoretical models, and simulation.

Specifically, calculated values for in situ wave energy dissipation were compared against values predicted by theoretical calculations to ensure their gross agreement. Additionally, the offshore components of energy flux for said in situ values have been shown to be insignificant throughout the periods of interest which further validates the assumption underlying their neglect in the analysis. It also provides supplementary evidence as to the veracity of the retained spectral components and the proposed mechanism by which the flux divergence reversal takes place.

Investigating the sources and sinks in the theoretical wave energy balance which

allowed for the flux divergence reversal to occur, it was found that the greatest flux divergence reversal is seen with winds from the E to SE. This was shown to be consistent with theories suggesting shoreward energy flux as well as sediment transport and resuspension prior to cold front passage.

Then, analysis of available burst and burst averaged ABS data from the instrumented stations allowed for a better understanding of the dynamic nature of the 
fluid-mud and an investigation of the respective magnitudes of $h_{m u d}$ and $\delta^{1}$. And looking at the thickness of the mud layer during the E to SE squalls one can compare the relative magnitudes of their effect on the energy flux and also compare in situ measurements to the aforementioned theoretical model as a means of validation.

Lastly, looking briefly at measures of the error in the calculated values for energy flux it was shown that the variance was rather large at times. And although one measure of error found it to be of the same magnitude as the underlying signal, a large portion of the variation could be attributed to physical distance between the sensors. Furthermore, the data presented has been shown to be consistent when compared to measurements gathered from other instruments utilized during the same deployment. Therefore, The error analysis suggests that one can not determine if an actual reversal took place, particularly since since the SWAN analysis does not support a reversal in the frequency band of interest, but does support that flux divergence decreased relative to pre-storm values in the shallow waters investigated.

\footnotetext{
${ }^{1}$ given an estimate for $\nu$ - as discussed previously
} 


\section{Appendix A}

\section{Wind Input Calculations}

$$
\begin{gathered}
S_{\text {wind }}=A+B \cdot E, \text { for } E<E_{\text {lim }} \text { and }\left|\theta-\theta_{w}\right|<\frac{\pi}{2} \\
A=\frac{\beta_{1}}{2 \pi} \frac{\pi}{g^{3}} C_{d r a g}^{3}\left(\frac{\rho_{a}}{\rho_{w}}\right)^{3}\left(U_{10} \cdot \max \left(0, \cos \left(\theta-\theta_{w}\right)\right)\right)^{4}, \sigma>0.7 \sigma_{P M, d} \\
B=\max \left(0, \beta_{2} \frac{5}{2 \pi} \frac{\rho_{a}}{\rho_{w}}\left(\frac{U_{10}}{\sigma / k} \cos \left(\theta-\theta_{w}\right)-\beta_{3}\right)\right) \sigma \\
\beta_{1}=188 \\
\beta_{2}=0.59 \quad \bar{d}=\frac{g d}{U_{10}^{2}} \\
\beta_{3}=0.12 \quad \sigma_{P M, d}=\frac{\sigma_{P M}}{\tanh \left(0.833 d^{0.375}\right)} \\
C_{d r a g}=0.0012 \quad c
\end{gathered}
$$

$\sigma$ - radian (angular) frequency $[\mathrm{rad} / \mathrm{sec}]$

$\mathbf{k}$ - wavenumber $[1 / \mathrm{m}]$

$\theta$ - discrete spectral wave direction $[\mathrm{rad} / \mathrm{Hz}$.

$\theta_{w}$ - discrete spectral wind direction $[\mathrm{rad} / \mathrm{Hz}$.

E - Spectral Energy Density $\left[J / m^{2} \cdot H z\right.$. $]$ 
Undertaking these calculations with a subset of the data from the March 2010 deployment, from around day 4.3 to day 8.2, which corresponds to the set-up for one of the cold fronts, the median $S_{\text {wind }}$ was found to be $0.1051 \mathrm{~W} / \mathrm{m}^{2}$.

These definitions and relations are as per the development in the SWAN manual ${ }^{1}$. Specifically, relations from Cavaleri and Malanotte-Rizolli (1981), Holthuijsen and de Boer (1988), Holthuijsen et al. (1996), Shore Protection Manual (1973), PiersonMoskowitz (1964), and Snyder et al. (1981) were employed in this development.

For the 1-D SWAN numerical calculations, the given inputs were important:

WIND VEL $=8.0 \mathrm{DIR}=180$

BOUN SHAPE JONSWAP 1.0 PEAK DSPR DEGR

BOUN SIDE S CLOCKW -

CON PAR 1.0 8.00180 .0010 .00

GEN3

BREAK CON 1.000 .73

FRIC JON 0.0067

\footnotetext{
${ }^{1}$ Found at: http://swanmodel.sourceforge.net/online_doc/swantech/node20.html
} 


\section{Appendix B}

\section{Wave Calculations}

As we are working primarily with pressure signals, one first calculates the power spectral density of the pressure signal using Welch's method (for example) ${ }^{1}$ :

$$
S_{p p}(f)=\int_{-\infty}^{\infty} P(\tau) e^{-2 \pi i f \tau} \mathrm{d} \tau
$$

Then using a multiplicative factor of the form:

$$
H_{p}=\rho g \frac{\cosh k z}{\cosh k h}
$$

where $\rho$ is the density of the medium $\left[\mathrm{kg} / \mathrm{m}^{3}\right], g$ gravity $\left[\mathrm{m} / \mathrm{s}^{2}\right], k$ the wavenumber from the linear wave theory dispersion relation $[1 / m], z$ the height of pressure sensor off bottom $[m]$ (positive number), and $h$ the depth of the water column $[m]$. One can then calculate the surface spectrum as $S_{\eta p}=\frac{S_{p p}}{H_{p}^{2}}$ and for $\omega=2 \pi f$, one can integrate for the first spectral moment $(j=0)$ :

$$
m_{j}=\int_{0}^{\infty} \omega^{j} \cdot S_{\eta p}(\omega) \mathrm{d} \omega, \mathrm{j}=0,1,2, \ldots
$$

\footnotetext{
${ }^{1}$ Derivation culled primarily from Dean and Dalrymple, Water Wave Mechanics for Engineers \& Scientists, World Scientific Publishing Company 1991; Newman, Marine Hydrodynamics, The MIT Press 1977; and personal communications P. Traykovski, 2010-2011
} 
and significant wave height is simply:

$$
\bar{H}_{1 / 3}=H_{\text {sig }}=2 \sqrt{2 \cdot m_{0}}
$$

where a broadband spectrum has been assumed in the definition of $H_{\text {sig }}$, i.e. $\epsilon \rightarrow 1$ for $\epsilon=\sqrt{\frac{m_{2}^{2}}{m_{0} m_{4}}}$. If $\epsilon \approx 1$, i.e. for a broadband spectrum, $\bar{H}_{\frac{1}{3}}=H_{\text {sig }}=2 \sqrt{2 \cdot m_{0}} \Rightarrow$ $A=\sqrt{\left(2 \cdot m_{0}\right)}$.

Additionally, as this work is specifically interested in the swell band (from $0.05 \mathrm{~Hz}$. to $0.2 \mathrm{~Hz}$.) when one determines the spectral moments, and thus the contribution to significant wave height over that frequency band, one may just limit the band of integration and evaluates in a piecewise manner numerically over bins of frequencies (employing a trapezoidal or similar scheme).

To calculate energy flux, one first finds the spectral wave energy (or energy density per unit frequency) and then integrating that over the band of interest directly from the spectral data:

$$
\bar{E}=\int_{\text {swell }} \frac{1}{2} \rho g S_{\eta p} \mathrm{~d} f=\frac{1}{2} \rho g A^{2}
$$

and for energy flux defined as $F=\bar{E} \cdot C_{g}$ with group velocity defined as $C_{g}=\frac{\partial \omega}{\partial k}$ it can be determined in closed form from the dispersion relation given as $\omega=(g k$. $\tanh (k h))^{1 / 2}$, in closed form

$$
C_{g}=\frac{g\left(h k \cdot \operatorname{sech}(h k)^{2}+\tanh (h k)\right)}{2 \sqrt{g k \cdot \tanh (h k)}}
$$

combining equations B.1 and B.2 yields energy flux $(\mathrm{F}$ in $[\mathrm{W} / \mathrm{m}])$ to be $F=\bar{E} \cdot C_{g}$.

A problem with the above though, is that the equations all presume perfect onshore transit of the waves and a real wave field has an angular distribution of the incident waves, thus the above must be modified to account for that. The first modification is to note that $S(\omega)$ is now $S(\omega, \theta)$ where $\theta$ is the angular distribution of the spectrum with units of [rad/Hz.]. To be perfectly clear though, we actually have $\theta=\theta_{\text {wind }}-\theta_{\text {array }}$ where $\theta_{\text {wind }}$ is the spectral angular distribution of the incident waves; and $\theta_{\text {array }}$ is the angle of the array from North (azimuth) ${ }^{2}$. 
We can now calculated a projection to North based on $\theta$. For the projection, we need Real $\left\{\overline{C_{g, c o m p} \cdot S\left(\omega, \theta_{\text {swell }}\right)}\right\}$ and $\overline{\left\|C_{g, \text { comp }} \cdot S\left(\omega, \theta_{\text {swell }}\right)\right\|}$, which the former is calculated as

$$
\operatorname{Real}\left\{\overline{C_{g, \text { comp }} \cdot S\left(\omega, \theta_{\text {swell }}\right)}\right\}=\operatorname{Real}\left\{\overline{\int_{\text {swell }} C_{g, \text { comp }} \cdot S\left(\omega, \theta_{\text {swell }}\right) \mathrm{d} \omega}\right\}
$$

Thus the projection is

$$
\alpha_{\text {swell }}=\operatorname{Real}\left\{\overline{C_{g, \text { comp }} \cdot S\left(\omega, \theta_{\text {swell }}\right)}\right\} / \overline{\left\|C_{g, \text { comp }} \cdot S\left(\omega, \theta_{\text {swell }}\right)\right\|}
$$

for a complex group velocity $C_{g, c o m p}=C_{g} \cdot \cos (\theta)+i \sin (\theta)$ and $\theta_{\text {swell }}$ indicating that again, only the frequency content between 0.05 and 0.2 Hertz was included. Given the projection, one can shore-normal (and in our case swell-band) energy flux via

$$
F=\left\{\int_{\text {swell }} \operatorname{Real}\left\{C_{g, \text { comp }}\right\} \cdot S\left(\omega, \theta_{\text {swell }}\right) \mathrm{d} \omega\right\} \cdot \alpha_{\text {swell }}
$$

Then, given swell-band shore-normal energy flux, flux divergence is simply a first difference, and dissipation is similar - given the the theoretical development in Kranenberg [2008]. Calculating a finite difference flux divergence will take the form:

$$
\frac{d F}{d x}=\frac{F_{2}-F_{1}}{\Delta x}
$$

and in order to then calculate dissipation, one also need define an average energy flux:

$$
\bar{F} \doteq \frac{F_{1}+F_{2}}{2}
$$

where in both the above equations, $F_{1}$ and $F_{2}$ are placeholders for the energy flux at any of the three stations and the $\Delta x$ can be determined directly from the stations' GPS coordinates collected during the deployment.

\footnotetext{
${ }^{2}$ The effect of $\theta_{\text {array }}$ due to the orientation of the $7 \mathrm{~m}$ and $3 \mathrm{~m}$ stations of the array with respect to North is minor. It is on the order of $4^{\circ}$, but it bears noting none-the-less.
} 


\section{Bibliography}

TP Barnett. On the generation, dissipation, and prediction of ocean wind waves. $J$. Geophys. Res., 73(2):513-529, 1968.

DJT Carter. Prediction of wave height and period for a constant wind velocity using the jonswap results. Ocean Engineering, 9(1):17-33, 1982.

R.L Crout and R.D Hamiter. Response of bottom waters on the west louisiana shelf to transient wind events and resulting sediment transport. Transactions of the Gulf Coast Association of Geological Societies, XXXI:273-238, Mar 1981.

RA Dalrymple and PLF Liu. Waves over soft muds: a two-layer fluid model. Journal Of Physical Oceanography, 8(6):1121-1131, 1978.

PJ deWit. Liquefaction of cohesive sediments caused by waves. PhD Thesis, pages 1-211, Apr 1995.

PJ deWit and C Kranenburg. The wave-induced liquefaction of cohesive sediment beds. Estuar Coast Shelf S, 45(2):261-271, Jan 1997.

AE Draut, GC Kineke, OK Huh, JM Grymes III, KA Westphal, and CC Moeller. Coastal mudflat accretion under energetic conditions, louisiana chenier-plain coast, usa. Marine Geology, 214(1-3):27-47, 2005a.

AE Draut, GC Kineke, DW Velasco, MA Allison, and RJ Prime. Influence of the atchafalaya river on recent evolution of the chenier-plain inner continental shelf, northern gulf of mexico. Cont Shelf Res, 25(1):91-112, $2005 \mathrm{~b}$.

D Eisma and J Kalf. Dispersal of zaire river suspended matter in the estuary and the angola basin. Netherlands Journal of Sea Research, Jan 1984.

S Elgar and B Raubenheimer. Wave dissipation by muddy seafloors. Geophys Res Lett, 35(7):L07611, Jan 2008. doi: 10.1029/2008GL033245.

H.G Gade. Effects of a nonridid, impereable bottom on plane surface waves in shallow water. Journal of Marine Research, 16:61-82, Feb 1958.

K Hasselmann. On the spectral dissipation of ocean waves due to white capping. Boundary-Layer Meteorology, 6(1):107-127, 1974. 
T.-J Hsu, P. A Traykovski, and G. C Kineke. On modeling boundary layer and gravity-driven fluid mud transport. J. Geophys. Res., 112(C4):C04011, Apr 2007.

OK Huh, ND Walker, and C Moeller. Sedimentation along the eastern chenier plain coast: Down drift impact of a delta complex shift. Journal of Coastal Research, 17 (1):72-81, 2001.

S Jaramillo, A Sheremet, and M Allison.... Wavemud interactions over the muddy atchafalaya subaqueous clinoform, louisiana, united states: Wavesupported sediment transport. Journal of Geophysical Research, Jan 2009.

G.P Kemp and J.T Wells. Atchafalaya mud stream and recent mudflat progradation: Louisiana chenier plain. Gulf Coast Association of Geological ..., Jan 1981.

GC Kineke, RW Sternberg, JH Trowbridge, and WR Geyer. Fluid-mud processes on the amazon continental shelf. Continental Shelf Research, Jan 1996.

W Kranenberg. Modelling wave damping by fluid mud. MSc. Thesis, pages 1-156, Feb 2008.

$\mathrm{H}$ MacPherson. The attenuation of water waves over a non-rigid bed. J. Fluid Mech, 97(4):721-742, 1980.

C Ng. Water waves over a muddy bed: a two-layer stokes' boundary layer model. Coastal Engineering, Jan 2000.

HH Roberts, OK Huh, SA Hsu, LJ Rouse Jr, and DA Rickman. Winter storm impacts on the chenier plain coast of southwestern louisiana. Transactions of the Gulf Coast Association of Geological Societies, 39:515-522, 1989.

P Traykovski, WR Geyer, JD Irish, and JF Lynch. The role of wave-induced densitydriven fluid mud flows for cross-shelf transport on the eel river continental shelf. Cont Shelf Res, 20(16):2113-2140, 2000.

P Traykovski, PL Wiberg, and WR Geyer. Observations and modeling of wavesupported sediment gravity flows on the po prodelta and comparison to prior observations from the eel shelf. Cont Shelf Res, 27(3-4):375-399, 2007.

J Winterwerp, R Graaff, and J Groeneweg.... Modelling of wave damping at guyana mud coast. Coastal Engineering, Jan 2007.

LD Wright and JM Coleman. Mississippi river mouth processes: effluent dynamics and morphologic development. The Journal of Geology, 82(6):751-778, 1974. 